\title{
POLY(ADP-RIBOSYL)ATION AFFECTS STABILIZATION OF CHE-1 PROTEIN IN RESPONSE TO DNA DAMAGE
}

\author{
Dr. Maria Giulia Bacalini
}

Dottorato di ricerca in

Biologia Umana e Genetica

XXIII ciclo 


\title{
POLY(ADP-RIBOSYL)ATION AFFECTS STABILIZATION OF CHE-1 PROTEIN IN RESPONSE TO DNA DAMAGE
}

\author{
Candidate: Maria Giulia Bacalini \\ Academic year 2009/2010 \\ XXIII cycle
Ph.D. program: "HUMAN BIOLOGY AND GENETICS"
Department of Cellular Biotechnology and Hematology
SAPIENZA UNIVERSITY OF ROME

Director of doctoral program:

Prof. Paola Londei

Department of Cellular Biotechnology and Hematology, Sapienza University of Rome

Scientific Tutor:

Prof. Anna Reale (professor of Clinical Biochemistry and Molecular Biology)

Department of Cellular Biotechnology and Hematology, Sapienza University of Rome

Board of examiners:

Prof. Mara Riminucci

Sapienza University of Rome

Prof. Maria Malanga

University Federico II, Naples

Prof. Anna La Teana

Polythecnic University of "The Marche", Ancona

Prof. Anna Tramontano

Sapienza University of Rome 



\section{INDEX}

$\begin{array}{ll}\text { Abstract } & 3\end{array}$

\section{Introduction}

A unique insurance policy for the cell: the DNA damage response

Organization of the DNA damage response: the ATR-Chk1 and

ATM-Chk2 pathways

Che-1, a newly identified player in DNA damage response

Poly(ADP-ribosyl)ation reactions

PARP-1 in DNA damage response

Aim of the thesis

Experimental procedures

\section{Results}

Effect of doxorubicin treatment on PARP activity

PARP-1 activity is required for efficient Che- 1 accumulation in doxorubicin treated cells

3-aminobenzamide treatment of doxorubicin-exposed HCT116 cells

reduces Che-1 recruitment on $p 21$ promoter and impairs $p 21$ transcription

PARP activity cooperates with ATM kinase activity to stabilize Che-1

Che-1 co-immunoprecipitates with ADP-ribose polymers but it does not bind them non-covalently

Che-1 interacts with PARP-1 in vivo and in vitro

Che-1 is poly(ADP-ribosyl)ated by PARP-1 in vitro and in vivo 
Discussion

References 


\section{$\underline{\text { ABSTRACT }}$}

Post-translation modifications play a crucial role in coordinating the cellular response to DNA damage.

Double strand DNA breaks (DSBs) trigger the activation of ATM and Chk2 kinases, which represent the primary transducers in the signalling cascade. Among the high number of phosphorylated proteins, our attention was focused on Che-1, a novel ATM and Chk2 substrate whose role in DNA damage response has been recently shown. Phosphorylated Che1 accumulates and promotes transcription of p53 and p53-responsive genes, which are critical for the maintenance of G2 arrest and for DNA repair processes.

Poly(ADP-ribosyl)ation is a post-translational modification that shows an emerging role in the signal transduction to the DDR machinery. Poly(ADP-ribose) polymerase 1 (PARP-1), the main enzyme involved in this modification, is recruited on DNA lesions and catalyzes the synthesis of ADP-ribose polymers (PAR) on itself and on target proteins. In particular, a recent work demonstrated that PAR synthesis at DSBs sites is necessary to recruit ATM kinase, which can interact non-covalently with PAR.

In this study we showed that poly(ADP-ribosyl)ation, beyond phosphorylation, is involved in the regulation of Che-1 stabilization following DNA damage. We demonstrated that Che-1 accumulation upon doxorubicin treatment is reduced after inhibition of PARP activity in HCT116 cells and in PARP-1 knock-out or silenced cells. In accordance, impairment in Che-1 accumulation by PARP inhibition reduced Che-1 occupancy at $p 21$ promoter and affected the expression of the corresponding gene. Epistasis experiments showed that the effect of poly(ADP-ribosyl)ation on Che-1 stabilization is independent from ATM kinase activity. Indeed we demonstrated that Che- 1 protein co-immunoprecipitates with PAR and that PARP1 directly interacts with Che-1, promoting its modification in vitro and in vivo.

Altogether, these findings suggest that poly(ADP-ribosyl)ation of Che-1 represents a mechanism enabling the precise control over the level of Che-1 protein in response to DNA damage. 


\section{INTRODUCTION}

\section{A unique insurance policy for the cell: the DNA damage response}

Each of the cells in our body receives tens of thousands of DNA lesions every day (Lindahl and Barnes, 2000). Environmental sources of damage include ultraviolet (UV) light, ionizing radiations (IR) and chemicals in tobacco smoke or in contaminated food. However, much of DNA damage arises from endogenous sources as a consequence of normal cellular metabolism. DNA mismatches and breaks are occasionally produced during replication or following abortive topoisomerase activity. Moreover, reactive oxygen compounds are byproducts of oxidative respiration or are produced, together with nitrogen compounds, during inflammation processes (Kawanishi et al., 2006).

DNA lesions can impair replication and transcription reactions and produce mutations and genomic rearrangements. As a consequence, they can induce senescence or cell death and affect organism's development and ageing. Moreover, genomic instability greatly predisposes the organism to immunodeficiency, neurological disorders and cancer (Hakem, 2008; Subba Rao, 2007; Thoms et al., 2007).

To cope with DNA damage and prevent its propagation across cell divisions, cells have evolved a special "insurance policy" commonly referred as DNA damage response (DDR) (Harper and Elledge, 2007). The DDR is a complex and versatile network of mechanisms that coordinates the physical detection of the damage with the activation of signalling pathways highly interconnected and regulated in space and time. These pathways control the relaxation of chromatin structure to facilitate the repair, the recruitment and the activation of repair factors to the DNA damage site and the concomitant block of cell cycle by checkpoints. If the damage is too intense, DDR activates senescence or the apoptotic program (Figure 1).

Distinct DNA repair mechanisms deal with the wide variety of structurally different DNA lesions (Figure 2) (Hakem, 2008). The direct lesion reversal repairs $O^{6}$-alkylguanine induced by alkylating agents, while the small insertions and deletions produced during replication are the substrate of the mismatch repair. Helix distorting lesions and base damage, the most common insult to DNA, are repaired respectively by the nucleotide excision repair and the base excision repair. Although less frequent than other lesions, double-strand DNA breaks (DSBs) are the most cytotoxic of all DNA lesions. DSBs are caused by IR and radiomimetic compounds, but are also generated when the replication machinery encounters single strand 


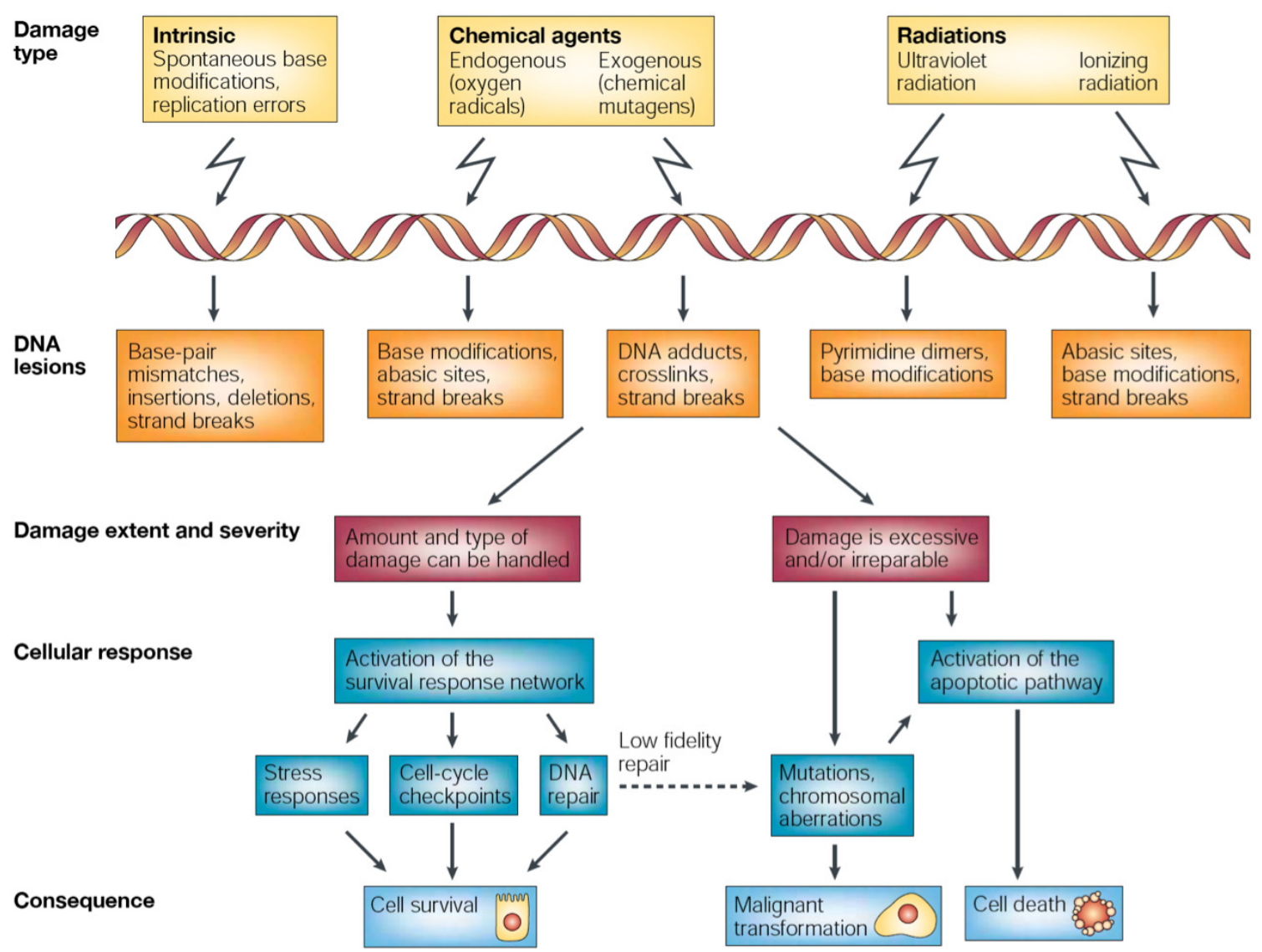

Figure 1. The DNA damage response. The cell response to DNA insults (survival or death pathways) depends on the type and the extent of the damage. A complex network of signalling pathways regulates these choices at the molecular level. Failure in correct repair can lead to malignant transformation (adapted from Shiloh 2003).

breaks (SSBs). Two distinct but partially complementary pathways act to repair DSBs: the non-homologous end-joing, an error-prone mechanism in which the two DNA ends are ligated together, and the homologous recombination, which relies on the presence of a homologous 
DNA molecule that can be copied to repair the damage. Although more accurate than NHEJ, HR operates only at the $\mathrm{S}$ or $\mathrm{G}_{2}$ phase of the cell cycle, and NHEJ is the predominant mechanism of DSBs repair in higher eukaryotes.

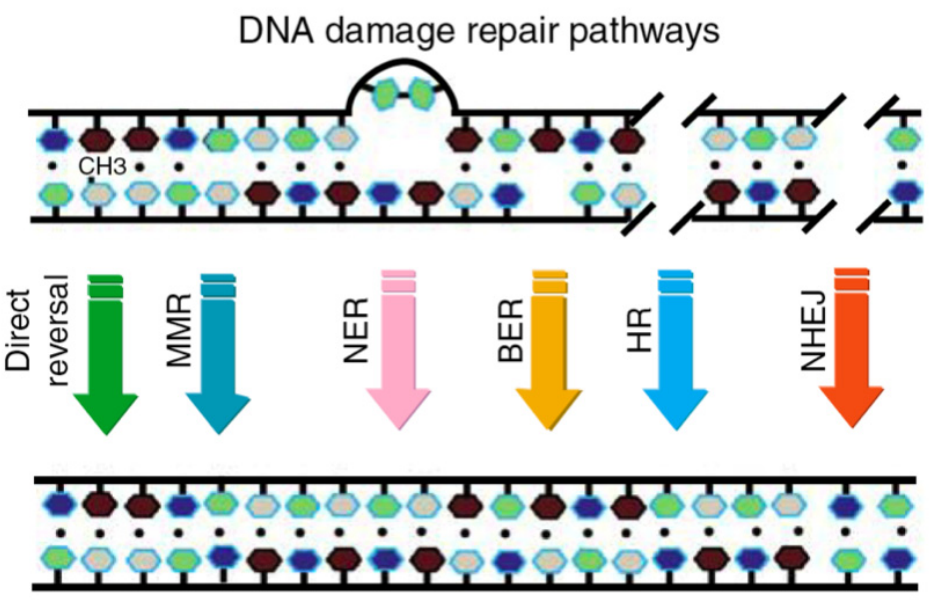

Figure 2. DNA-repair pathways. Different mechanisms repair the high number of structurally distinct DNA lesions (adapted from Hakem 2008).

In the past decade the interest in the DDR field has enormously increased. On one side it is evident that, in exercise of its role as "guardian" of the genome, DDR represents an essential anticancer barrier (Bartkova et al., 2005; Gorgoulis et al., 2005). Indeed, defects in DDR components impair genomic integrity and create a permissive environment for cancer evolution. Conversely, DNA damaging agents are widely used in anticancer therapy. Tumour cells are often characterized by genomic instability and high proliferative rates, and are therefore preferential targets of DNA damaging agents with respect to normal cells. However, activation of DDR in cancer cells might reduce the effectiveness of DNA damaging therapies and result in resistance to treatment (Zhou and Bartek, 2004). The selective inhibition of DDR in tumour cells could therefore sensitize them to DNA damaging agents (chemosensitization). Moreover, current advances show that specific defects in DDR often occurring in cancer cells are synthetically lethal with the inhibition of complementary repair pathways and can therefore be exploited for cancer therapy (Reinhardt et al., 2009). 
For these reasons, a great effort has been devoted to understand the signal-transduction pathways that mediate response to DNA damaging agents in normal and cancer cells.

\section{Organization of the DNA damage response: the ATR-Chk1 and ATM-Chk2 pathways}

The DDR is a multifaceted pathway that promptly adapts to the nature of DNA damage and to the stage of the cell cycle in which the lesion occurs. Indeed, the same DNA insult can activate different DDR pathways in different cell type contexts. The various DDR mechanisms have a common general organization (Figure 3) (Jackson and Bartek, 2009), but it is important to underlie that all the components of DDR are highly interconnected and reciprocally regulated. At least in the first phases, the regulation of cellular response to DNA damage strongly depends on post-translational modifications of proteins, which provide a rapid and reversible way to modulate protein-protein interactions and regulate protein trafficking, activity and stability (Huen and Chen, 2008).

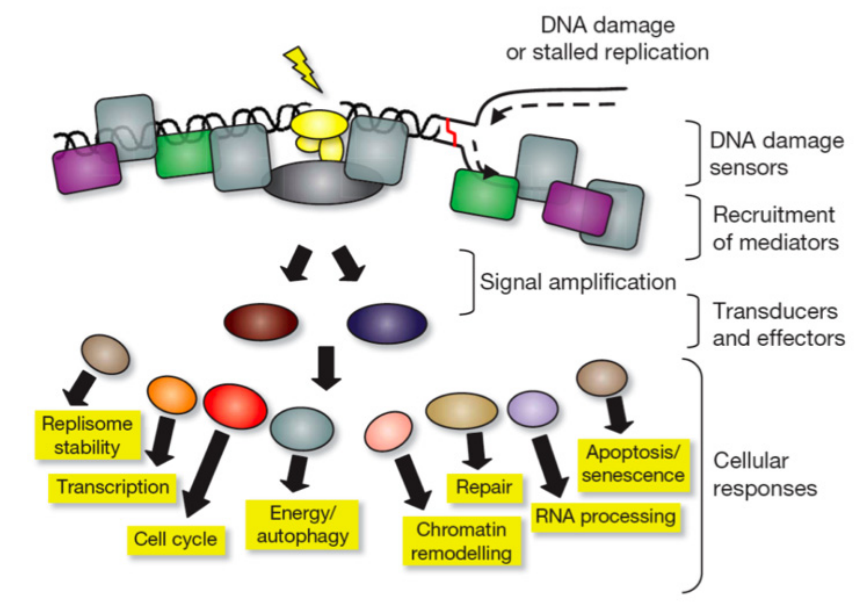

Figure 3. Conceptual organization of the DDR. DNA lesions are recognized by sensor proteins that, through specific mediators, transmit the signal to transducer and effector components. Many of the transducer and effector proteins promote post-translational modifications of their targets in order to activate the appropriate cellular responses (adapted from Jackson 2009). 
At the core of DDR there are the transducer kinases ATR (ataxia telangiectasia and Rad3 related) and ATM (ataxia telangiectasia mutated) and their substrates checkpoint kinase 1 (Chk1) and 2 (Chk2) (Figure 4) (Shiloh, 2003; Smith et al.).

ATM and ATR are large serine/threonine kinases which belong to the phosphatidylinositol-3kinase (PI3K) family, but which act only on proteic substrates (Abraham, 2001).

ATM was identified in 1995 as the product of the gene mutated in the autosomal recessive syndrome ataxia telangiectasia (A-T), a genomic instability disorder. ATM is present in undamaged cells as an inactive homodimer (Bakkenist and Kastan, 2003). Following DSBs formation, ATM is rapidly recruited to damage sites by association with the sensor complex MRN [MRE11 (meiotic recombination 11)-RAD50-NBS1 (Nijmegen breakage syndrome 1)] (Lee and Paull, 2005) and autophosphorylates at S1981, S367 and S1893 residues (Kozlov et al., 2006), leading to dissociation of the homodimer in active monomers.

Unlike ATM, ATR is predominantly activated by single strand DNA (ssDNA) tracts (Cimprich and Cortez, 2008) that are generated when DNA replication is impeded - for example following UV light exposure, or as a consequence of nucleolytic strand resection during HR repair (Jazayeri et al., 2006). ssDNA tracts are rapidly coated with a trimeric complex, called Replication Protein A (RPA), which recruits ATR via its partner ATRIP (Zou and Elledge, 2003). ATR activation is not dependent on post-translational modifications of the kinase, but depends on recruitment of two mediator proteins, TopBP1 (Delacroix et al., 2007) and Claspin (Freire et al., 2006).

In a recent screening, hundreds of potential substrates of ATM and ATR kinases have been identified (Matsuoka et al., 2007). ATM/ATR signalling pathways enhance repair by recruiting, activating and inducing repair factors. In parallel, they activate cell cycle checkpoints, which slow down or arrest the cycle in order to allow the cell to repair the damaged DNA before progression to the next phase. Progression through the cell cycle is regulated by Cyclin-CDK (Cyclin-dependent-kinases) complexes. Although distinct CyclinCDK complexes act in the different phases of the cycle, they are regulated by a common mechanism in which phosphorylation of CDKs negatively affects the activity of the complex. These phosphorylation events are counteracted by the activity of Cdc25 phosphatase family. Following DNA damage, ATM and ATR phosphorylate the kinases Chk2 and Chk1 respectively (Smith et al., 2010). In turn, activated Chk2 and Chk1 phophorylate Cdc25s and target them to proteosomal degradation, thereby enhancing CDKs phosphorylation and inhibiting cell cycle progression (Smith et al., 2010). Chk1, which is predominantly expressed in S and G2 phases in proliferating cells (Kaneko et al., 1999), is activated by ATR by a broad 
spectrum of DNA damaging agents and mainly regulates $\mathrm{S}$ and G2-M checkpoints. Chk2 is activated primarily by ATM in response to DSBs, although phosphorylation by ATR and DNA-PK can also occur (Hirao et al., 2002; Li and Stern, 2005; Matsuoka et al., 2000). Chk2 seems to play a partially redundant and supportive role in checkpoints control, while it seems to be more important for regulation of apoptosis upon DNA damage (Stracker et al., 2009; Zhou and Bartek, 2004). However, it is important to underline that ATR-Chk1 and ATMChk2 pathways are significantly interconnected and that among the wide number of Chk1 and Chk2 substrates, many are common to ATM and ATR (Stracker et al., 2009).

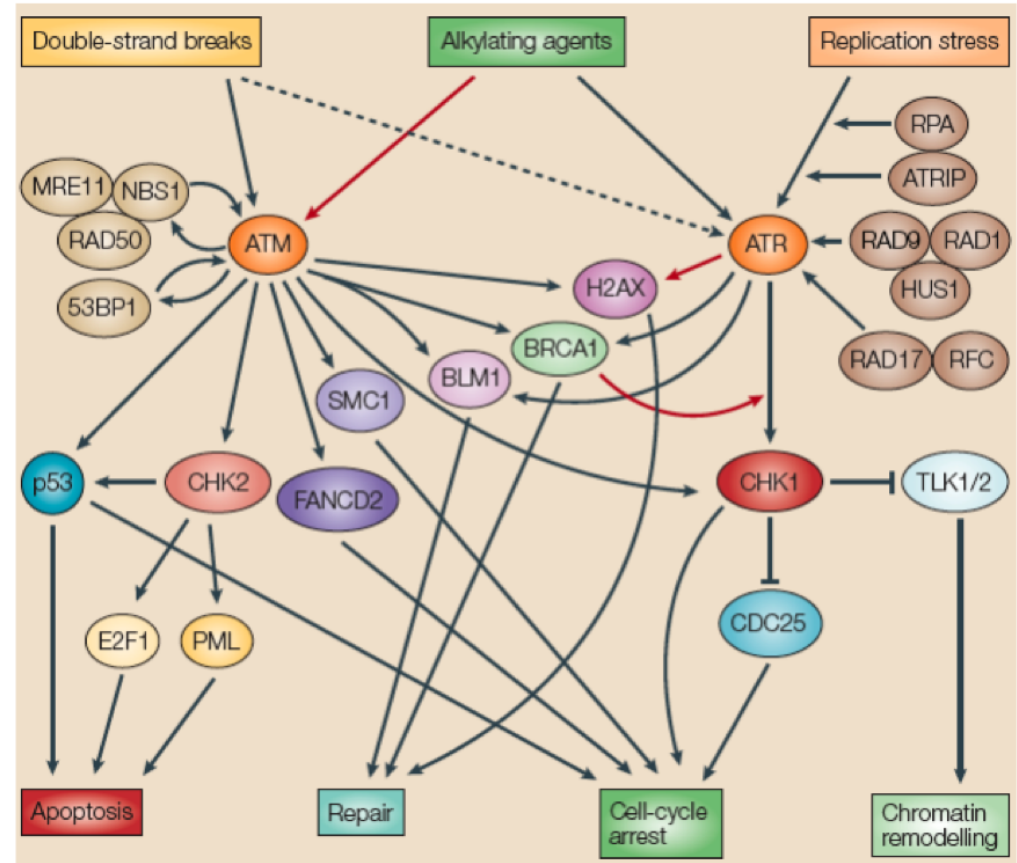

Figure 4. The ATM-Chk2 and ATR-Chk1 pathways in DDR. Upon DNA damage, the activation of the kinases ATM, ATR and of their substrates Chk2 and Chk2 promotes the adaptative response of the cell (adapted from Zhou and Bartek, 2004). 


\section{Che-1, a newly identified player in DNA damage response}

The human gene $A A T F$ (apoptosis antagonizing transcription factor) encodes for a 558 amino acids protein, commonly referred as Che-1, which is highly conserved among eukaryotes. Che-1 amino acidic sequence harbours two highly acidic regions at the amino-terminal, a central leucine zipper motif and three LXXLL receptor interaction motifs distributed throughout the protein (Passananti et al., 2007). Che-1 is predominantly a nucleolar protein (Andersen et al., 2005), but a cytosolic localization has been observed in neuronal cells (Barbato et al., 2003).

The first evidences regarding Che-1 function highlighted its strong anti-apoptotic activity (Figure 5). Page et al. (1999) demonstrated that Che-1 interacts with DAP-like kinase (DLK), a pro-apoptotic serine-threonine kinase, and antagonizes its function. In neural tissues Che-1 inhibits apoptosis induced by Par-4, a pro-apoptotic protein involved in aberrant production of $\beta$-amyloid peptide in Alzheimer's disease (Guo and Xie, 2004), and protects neuronal cells from $\beta$-amyloid induced cell death (Xie and Guo, 2004). Furthermore, execution of the apoptotic programme requires Che-1 degradation, which is regulated by the prolyl isomerase Pin1 (De Nicola et al., 2007) and, in neuronal cells, by the neutrophin receptor-interacting MAGE homolog NRAGE (Di Certo et al., 2007). Both proteins promote Che-1 ubiquitination and its proteasome-mediated degradation.

Moreover, Che-1 has an established role as transcriptional activator (Page et al., 1999), and its expression is essential during early stages of embryogenesis (Thomas et al., 2000). Although it does not directly bind DNA, Che-1 acts as a mediator which links the general transcription apparatus with different transcription factors, promoting the expression of target genes (Passananti et al., 2007). Che-1 amino acidic sequence shares some fragments of similarity with SV40 early gene large T antigen and with Escherichia coli $\sigma$-factor 70. Furthermore, Che-1 was identified as a binding partner of RBP11, the core subunit of human DNA Polymerase II which, together with RPB3, is the functional counterpart of the $\alpha$ subunit homodimer in Escherichia coli (Fanciulli et al., 2000). Che-1 has been shown to enhance transactivation activity of several steroid-receptors and to interact with the tumour suppressor TSG101, cooperatively stimulating androgen receptor-mediated transcription (Burgdorf et al., 2004).

Che-1 transactivation activity is pivotal in many steps of cell-cycle regulation (Figure 5).

Several experiments indicate that Che-1 acts as a general HDAC1 competitor in different cell contests. At the $\mathrm{G}_{1} / \mathrm{S}$ transition, Che1 was found to interact with the retinoblastoma $(\mathrm{Rb})$ 
protein and to promote cellular proliferation (Bruno et al., 2002). During $\mathrm{G}_{1}$ phase $\mathrm{Rb}$ interacts with the transcription factor E2F1 and recruits class I histone deacetylase proteins (HDACs) onto E2F1 target promoters, repressing the transcription of the corresponding genes. At the $\mathrm{G}_{1} / \mathrm{S}$ transition an increase in Che-1 protein levels, probably due to hyperphosphorylation of the protein, leads to a higher amount of Che-1-Rb complexes. This interaction displaces HDAC1 from the Rb-E2F1 complexes at the target promoters and relieves the inhibitory effect on transcription, stimulating therefore $G_{1} / S$ transition and cell proliferation. On the other side, overexpression of Che-1 in human colon carcinoma cells inhibits cell proliferation by activating the expression of the cyclin-dependent kinase inhibitor p21 (Di Padova et al., 2003). Che-1 can bind the transcription factor Sp1 and displace HDAC1 from its target sites in $p 21$ promoter. In line with these evidences, Che-1 has been found downregulated in several tumours, including colon and kidney carcinoma.

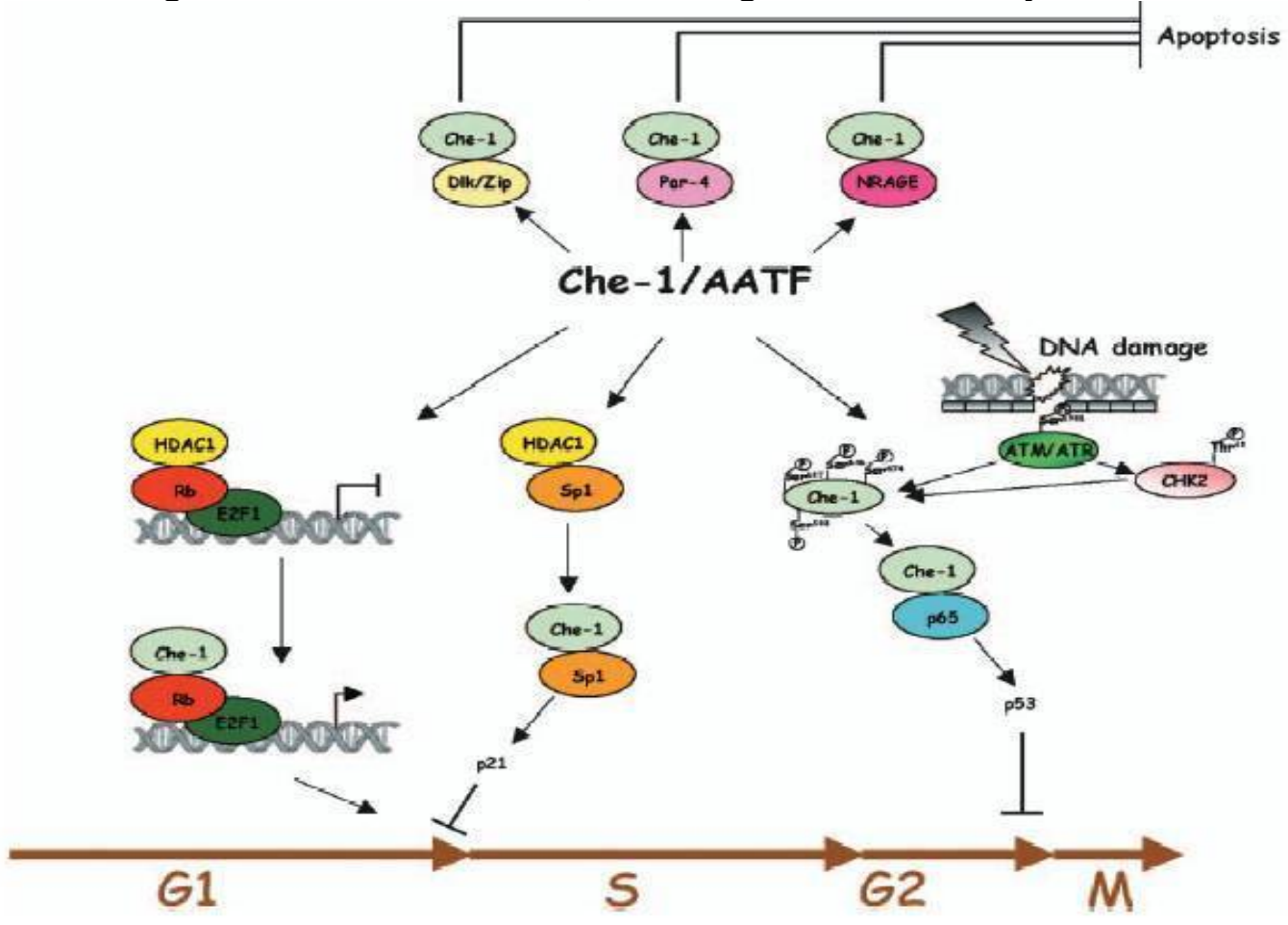

Figure 5. Multiple roles of Che-1 in cell-cycle and apoptosis regulation. See the text for details (adapted from Passananti et al., 2007). 
Recently, a role of Che-1 in DDR signalling has been evidenced (Bruno et al., 2006). In response to DNA damaging agents the kinases ATM, Chk2 and, to a less characterized extent, ATR and Chk1 phosphorylate Che-1 at four serine residues (Ser187 by ATM; Ser141, Ser474 and Ser508 by Chk2). This post-translational modification prevents Che-1 degradation by the proteasome and promotes its stabilization and accumulation. Moreover, phosphorylated Che-1 is recruited on the TP53 and $p 21$ promoters and activates the expression of the corresponding genes, contributing to the maintenance of the $\mathrm{G}_{2} / \mathrm{M}$ checkpoint in a p53-dependent way. Failure to maintain the $\mathrm{G}_{2} / \mathrm{M}$ checkpoint in Che-1 silenced cells leads to an increase in apoptosis and therefore in sensitivity to DNA damaging agents; notably, this effect is specific for cancer respect to normal cells. These observations prompted the authors to suggest Che-1 depletion as a therapeutic means to specifically sensitize tumour cells to anticancer agents (chemosensitization, see above). In line with these findings, in a recent work the same authors demonstrated that Che- 1 sustains mutant p53 expression in several tumour cell lines, and that silencing of Che-1 induces apoptotic cell death (Bruno et al., 2010).

\section{Poly(ADP-ribosyl)ation reactions}

ADP-ribosyl)ation is a post-translational modification of proteins which consists in the transfer of ADP-ribose units from nicotinamide adenine dinucleotide $\left(\mathrm{NAD}^{+}\right)$to glutamic acid, aspartic acid and lysine residues of acceptor proteins (Figure 6) (Freire et al., 2006). The ADP-ribose units can be linked via glycosidic ribose-ribose bonds forming highly negatively charged ADP-ribose polymers (PAR) containing 2-200 units, which can be linear or irregularly branched every 20-50 units. Beyond this covalent modification, a so called "noncovalent" modification has been extensively characterized. Indeed, PAR can interact with a number of target proteins which harbour specific PAR-binding consensus motifs. So far, three different PAR-interaction motifs have been identified: a 20 aminoacid consensus sequence rich in basic residues (Pleschke et al., 2000), a $\mathrm{C}_{2} \mathrm{H}_{2}$ zinc-finger referred as PBZ (Ahel et al., 2008) and a macrodomain structure (Ahel et al., 2009; Gottschalk et al., 2009; Timinszky et al., 2009). These interaction sequences often overlap with functional domains of target proteins, whose activity can therefore be modulated by binding to PAR. Although noncovalent, the interaction between PAR and the target protein results to be very strong and resists phenol partitioning, strong acids, detergents and high salt concentrations (Panzeter et al., 1992). Recently, a proteomic analysis of PAR binding proteins has revealed a wide 
number of PAR-interacting proteins (Gagne et al., 2008). At the present, 22 human proteins that possess an ADP-ribosyltransferase catalytic domain have been identified. These enzymes are historically referred as poly(ADP-ribose) polymerases (PARPs), although they effectively catalyze a transferase reaction and not a template-dependent polymerase reaction. Moreover, only two members of the family have a confirmed poly(ADP-ribosyl)transferase activity (PARP-1 and PARP-2) and can synthetize PAR on themselves (automodification) or on target proteins (heteromodification). Therefore a new unified nomenclature for this family has been recently proposed (Hottiger et al.).

Poly(ADP-ribose) polymerase-1 (PARP-1 or, according to the new nomenclature, ARTD1) is the founding member of the PARP family and is the main enzyme responsible for PAR production in the cell. It is an abundant and highly conserved nuclear protein of $116 \mathrm{kDa}$ that

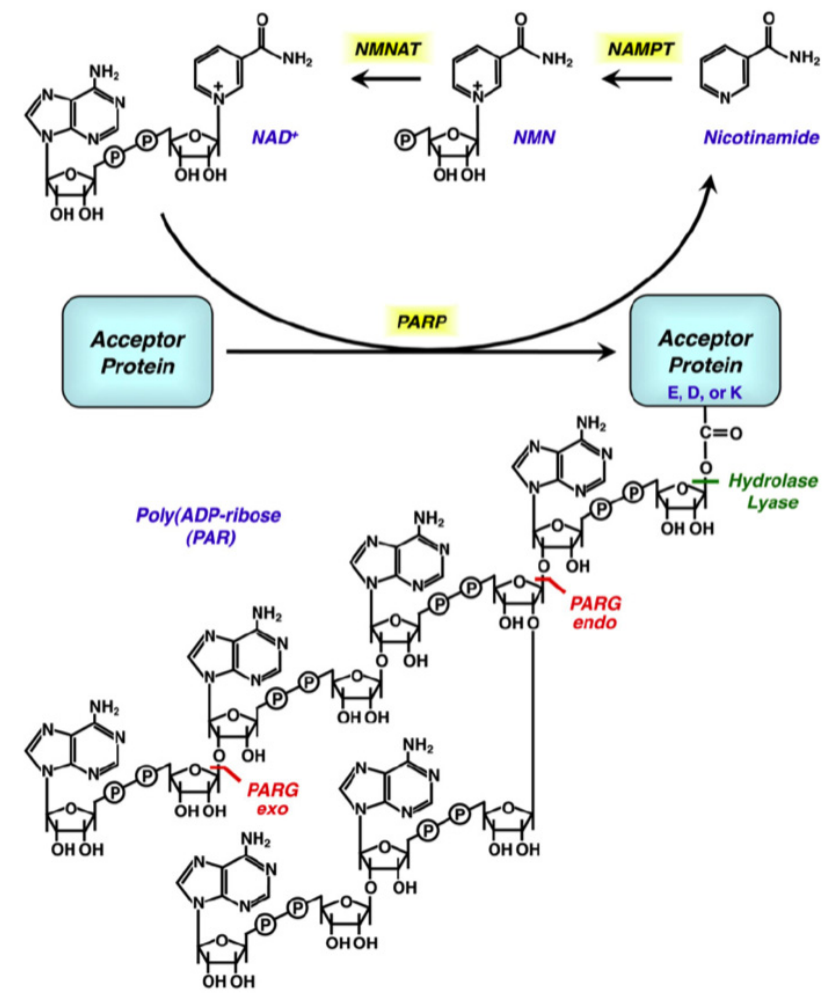

Figure 6. Catabolism and anabolism of PAR. The structure of a branched PAR is shown, such as the enzymatic actions of PARP, PARG and of the (ADP-ribosyl) protein lyase which removes the first monomer bound to the target protein.

$\mathrm{NAD}^{+}$, the substrate of PARP catalytic activity, can be synthetized from nicotinamide through the action of the enzymes nicotinamide phosphoribosyl transferase (NAMPT) and nicotinamide mononucleotide adenylyltransferase (NMNAT). Additional pathways of $\mathrm{NAD}^{+}$production (Schreiber 2006) are not reported. 
is ubiquitously expressed (Krishnakumar and Kraus). PARP-1 has a modular structure composed by:

- an amino-terminal DNA-binding domain (DBD), which contains two zinc-fingers that mediate binding to DNA and a third zinc-finger important for DNA-dependent activation of the enzyme (Langelier et al., 2008). The nuclear localization signal and a capsase- 3 cleavage site are also present in this domain;

- a central automodification domain (AD), which harbours PAR acceptor residues (Altmeyer et al., 2009) (Tao et al., 2009) and a BRCT fold (BRCA1 carboxy-terminal domain) which mediates protein-protein interactions and which is found in many DDR components;

- a carboxy-terminal catalytic domain (CD) which contains a highly conserved PARP signature motif for $\mathrm{NAD}^{+}$binding and a WGR (Trp, Gly, Arg) motif with unknown function.

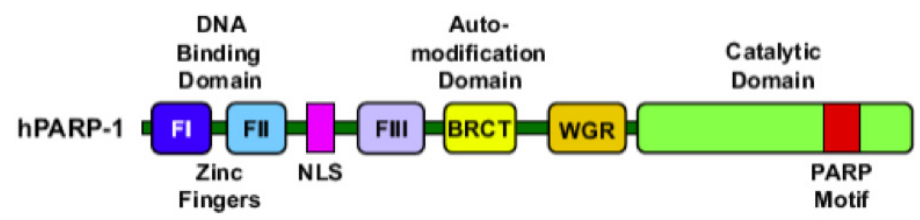

Figure 7. Structure of PARP-1. A schematic representation of human PARP-1. FI, FII and FIII: zincfinger domains; NLS: nuclear localization signal; BRCT, BRCA1 carboxy-terminal domain; WGR: WGR (Trp, Gly, Arg) motif; the PARP signature motif a the C-terminal of the protein is indicated in red (adapted from Krishnakumar 2010).

\section{PARP-1 in DNA damage response}

PARP-1 is involved in a wide range of cellular processes, which include chromatin structure and transcription, cellular signalling, regulation of cell-cycle and mitosis. However, the earliest and most characterized functions of PARP-1 are related to DNA repair and maintenance of genomic stability. Indeed, although viable, parp-1 knock-out mice show hyper-sensitivity to genotoxic stresses (Tong et al., 2001). Although to a lesser extent than PARP-1, also PARP-2 is activated following DNA damage, and can therefore have a compensatory effect in parp-1 knock-out models. According to this, parp-1/parp-2 double knock-out mice die early during embryogenesis. 
PARP-1 is a molecular sensor of both SSBs and DSBs generated by a variety of DNA damaging agents (D'Amours et al., 1999). PARP-1 binds as a dimer to these structures (Mendoza-Alvarez and Alvarez-Gonzalez, 1993) and its catalytic activity is stimulated up to 500 fold (Simonin et al., 1993) leading to intermolecular automodification of the enzyme or to heteromodification of target proteins. Automodification of PARP-1 upon DNA damage consists in the addition of PAR of heterogeneous length spanning from few to around 200 units (D'Amours et al., 1999). According to the "PARP shuttling" model (Figure 8), the progressive addition of negative charges during PARP-1 automodification gradually decreases the affinity of the enzyme for DNA up to a repulsion point in which PARP-1 dissociates from DNA and its catalytic activity is inactivated. PARP-1 release allows the acces of repair factors

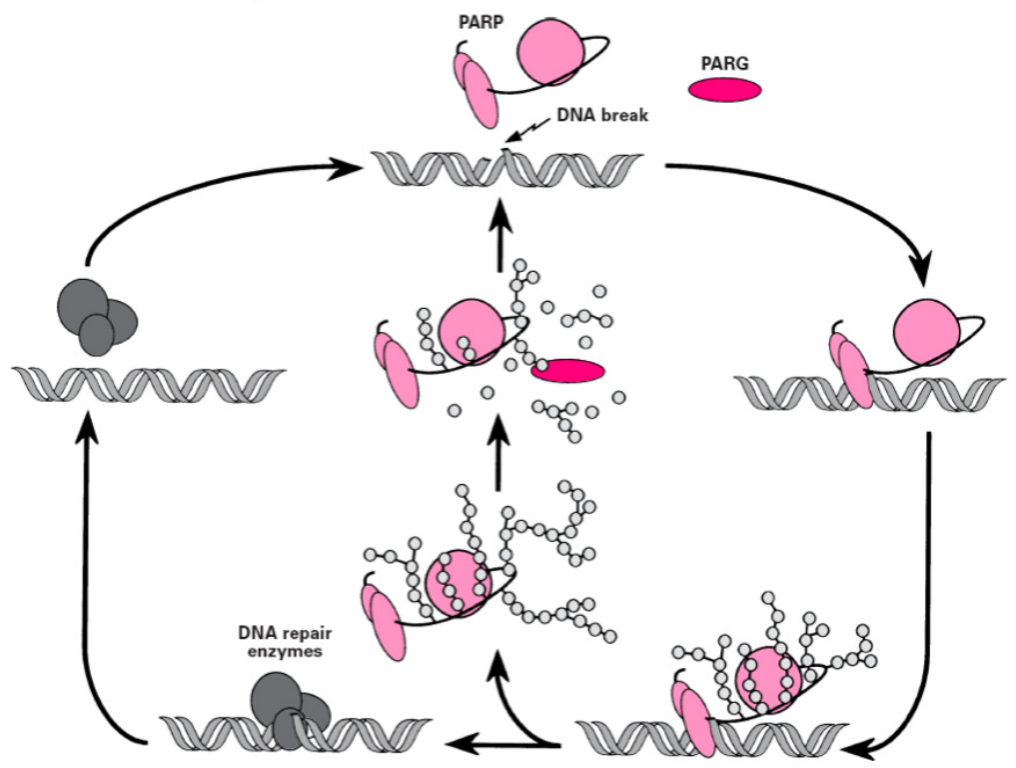

Figure 8. Shuttle model of

PARP-1. PARP-1 is activated upon recognition of DNA breaks. Automodification of PARP-1 increases the negative charge of the protein and reduces the affinity of the enzyme for DNA. When the electrostatic repulsion point is reached, the enzyme is released form DNA and its activity is inhibited. Reactivation of PARP-1 requires degradation of PAR by the PARG enzyme (adapted from D'Amours et al., 1999).

to DNA. The activity of poly(ADP-ribose) glycohydrolase (PARG), the enzyme which degrades PAR, guarantees the reactivation of PARP and the dynamic of this process.

The functional consequences of PARP activation depend on the extent of DNA damage. A transitory activation of PARP upon mild damage promotes the activation of repair and cellsurvival pathways. Over-activation of PARP-1 caused by severe DNA damage leads to $\mathrm{NAD}+$ and ATP depletion, and therefore to necrotic cell death. Contrariwise during apoptosis in order to avoid consumption of the ATP levels necessary for the execution of apoptotic program PARP-1 is inactivated through cleavage by caspase-3. Alternatively PARP-1 activity 
induces translocation of the apoptosis-inducing factor (AIF) from the mitochondria to the nucleus, resulting in a caspase-independent cell death (Cregan et al., 2002).

The local production of PAR at the DNA damage has a pivotal role in recruiting repair factors to DNA damage sites (Figure 9). For example, the scaffold protein XRCC1, which is necessary for the activation of BER machinery (El-Khamisy et al., 2003), harbours a PAR interaction motif and its recruitment to DNA lesions is affected by PARP inhibition (Okano et al., 2003). Similarly, other repair proteins, such as DNA ligase III (Leppard et al., 2003), proliferating cell nuclear antigen (PCNA) and the p150 subunit of chromatin assembly factor

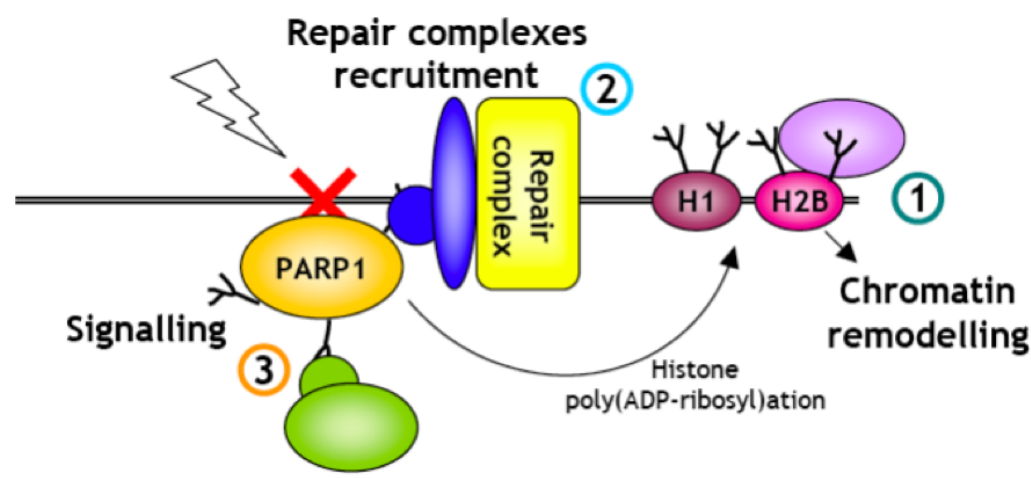

\author{
Figure 9. Roles of PARP-1 \\ in DDR. PAR production at the \\ DNA damage sites represents a \\ unique signal that mediates \\ chromatin remodelling, \\ recruitment of repair factors and \\ coordinates the transduction \\ cascade which allows the cell to \\ respond according to the severity \\ of the injury.
}

1 are recruited at DNA repair foci in a PAR-dependent way. At the same time both poly(ADP-ribosyl)ation of histones $\mathrm{H} 1$ and $\mathrm{H} 2 \mathrm{~B}$ and their non-covalent interaction with PAR lead to relaxation of chromatin, facilitating the access of the repair factors to DNA breaks.

In the recent years it has appeared clear that PARP-1 activity is also involved in the transduction of the signal induced by DNA damage, coordinating the local detection of DNA breaks with downstream cell responses. Many important checkpoint proteins, such as p21 and p53, harbours a PAR binding motif (Ahel et al., 2009; Pleschke et al., 2000). The PARbinding domain of p53 overlaps with its DNA binding domain (Malanga et al., 1998) and can therefore modulate the interaction with target sequences. Moreover, p53 can be covalently poly(ADP-ribosyl)ated by PARP-1, and this modification has been shown to be necessary for p53 nuclear accumulation upon DNA damage. Inhibition of PARP activity attenuates transcription of p21 (Madison and Lundblad, 2010; Wieler et al., 2003) and of the repair genes BRCA1 and RAD51 (Hegan et al., 2010). Further on, poly(ADP-ribosyl)ation of PARP1 has been recently reported to promote the assembly of a signalosome complex that ultimately leads to NF-kB activation in response to ionizing radiation (Stilmann et al., 2009). 
The role of PAR signalling in regulating the phosphorylation cascade initiated by the ataxia telangiectasia mutated (ATM) kinase has also been investigated. Despite initial conflicting results (Goodarzi and Lees-Miller, 2004; Watanabe et al., 2004), an association between ATM and PARP-1 in response to ionizing radiation has been described (Aguilar-Quesada et al., 2007) and recently ATM has been added to the list of PAR-binding proteins (Gagne et al., 2008; Haince et al., 2007). In particular, Poirier and coworkers (Haince et al., 2007) demonstrated that in the early phases of DNA damage induced by $N$-methyl- $N$ '-nitro- $N$ nitrosoguanidine (MNNG) PAR synthesis at DSBs is necessary to recruit ATM and induce the downstream response to damage, i.e. the phosphorylation of ATM targets such as p53. 
Although phosphorylation reactions play a pivotal role in coordinating DDR, other posttranslational modifications are involved in this complex pathway. Among these, poly(ADPribosyl)ation has been shown to be important not only in sensing DNA damage and recruiting repair factors, but also in regulating the signal transduction in DDR. In particular, the finding that PARP-1 can modulate ATM-mediated network prompted us to analyze the role of poly(ADP-ribosyl)ation in the regulation of Che1 levels, a newly identified ATM target which is stabilized following phosphorylation by DDR kinases (Figure 10).

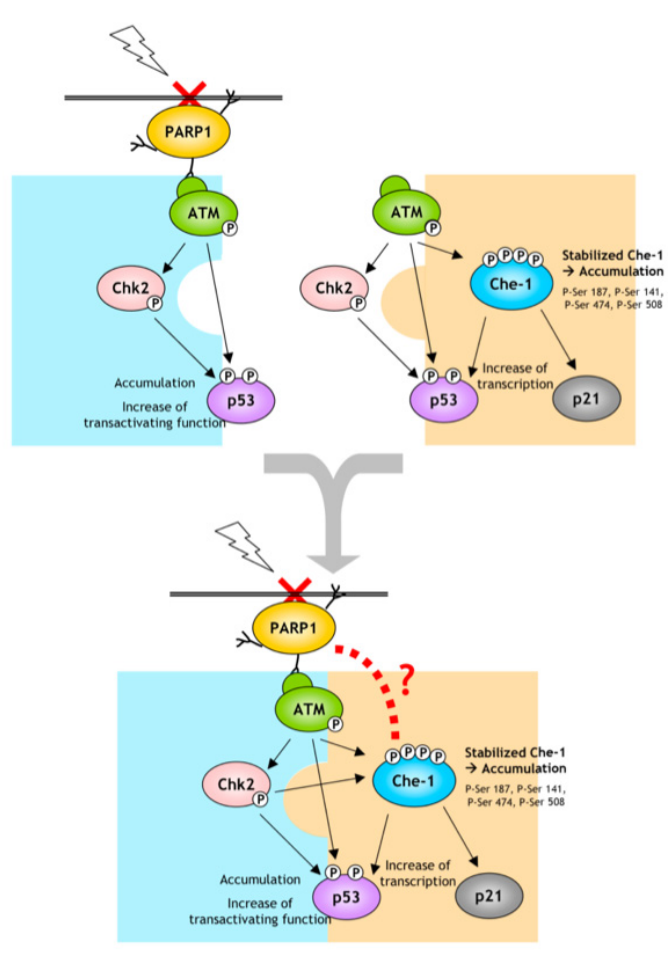

Figure 10. Aim of the thesis

We used as experimental models human colon carcinoma HCT116 cells and mouse embryonic fibroblasts derived from PARP $-1^{+/+}$and PARP $-1^{-/-}$mice. To induce DNA damage, cells were treated with doxorubicin (Doxo), an anthracycline antibiotic commonly used in chemotherapy. Doxo is a topoisomease II inhibitor that interferes with the religation step and leads to stabilization of the enzyme-DNA complex, eventually generating DSBs. Doxo treatment has been shown to induce stabilization of Che-1 through the activation of ATMChk2 and ATR-Chk1 pathways (Bruno et al., 2006). 


\section{EXPERIMENTAL PROCEDURES}

\section{Cell cultures and drug treatment}

Human colon carcinoma HCT116 cells and MEF derived from PARP- ${ }^{+/+}$and PARP- ${ }^{-/-}$mice (Wang et al., 1995) were grown in high glucose (4,5 g/litre) Dulbecco's modified Eagle's medium supplemented with $10 \%$ foetal bovine serum. SV40-transformed normal skin fibroblasts (GM00637) and ataxia-telangiectasia (A-T) fibroblasts (GM09607) were obtained from the Coriell Institute and grown in modified Eagle's medium supplemented with 10\% foetal bovine serum. All culture solutions were purchased from International PBI and supplemented with $2 \mathrm{mM}$ L-glutamine and 50 units/ml Penicillin-Streptomycin.

Cells were grown to about $70 \%$ confluence and when indicated were treated with doxorubicin (Sigma, final concentration $1 \mu \mathrm{M}$ ), 3-aminobenzamide (Sigma, final concentration $8 \mathrm{mM}$ ), PJ-34 (Alexis, final concentration $5 \mu \mathrm{M}$ ), KU55933 (Sigma, final concentration $10 \mu \mathrm{M}$ ).

\section{Antibodies}

The following mouse monoclonal antibodies were used: anti-PARP-1 (clone C2-10; Alexis), anti-PARP-1 (clone F1-23; Alexis), anti-PAR (clone 10HA; Trevigen), anti $\beta$-actin (clone AC-15; Sigma); anti-Myc (9E10 clone, hybridoma-conditioned medium); anti-P-histone H2AX (Upstate). Rabbit polyclonal antibodies used were anti-PARP-1 (Alexis) and anti-Che1 (Fanciulli et al., 2000).

\section{Western blotting}

Total cell extracts were obtained by lysis in RIPA buffer $(50 \mathrm{mM}$ Tris- $\mathrm{HCl} \mathrm{pH} 8.0,150 \mathrm{mM}$ $\mathrm{NaCl}, 1 \mathrm{mM}$ EDTA, $100 \mathrm{mM} \mathrm{NaF}, 3 \mathrm{mM}$ Na orthovanadate, $10 \%$ glycerol, 1\% NP-40) supplemented with protease inhibitors (complete EDTA-free, Roche Applied Science). Lysates were kept on ice for $20 \mathrm{~min}$ and then centrifuged at $16000 \mathrm{~g}$ for $20 \mathrm{~min}$ at $4^{\circ} \mathrm{C}$. Supernatants were collected and quantified by Bradford protein assay reagent (Bio-Rad). Equal protein amounts were separated by SDS-PAGE and electroblotted onto nitrocellulose membrane (Hybond ${ }^{\mathrm{TM}} \mathrm{ECL}^{\mathrm{TM}}$ GE Healthcare). Immunoblots probed with the specific antibodies were developed using ECL or ECL-PLUS chemioluminescence reaction (GE Healthcare). 


\section{Extraction of nucleic acids and qRT-PCR}

Total RNA was purified by RNeasy mini kit (Qiagen) and genomic DNA was digested by RNase-free DNase (Qiagen) treatment. RNA concentration and quality were evaluated by spectrophotometer analysis and agarose gel electrophoresis.

Total RNA $(2 \mu \mathrm{g})$ was subjected to retrotranscription using Superscript First-Strand Synthesis system (Invitrogen). Expression of Che-1 mRNA was measured by real time PCR using iCycler IQ detection system (Bio-Rad). In mouse cells, a Taq-Man gene expression assay (Applied Biosystems) was used and relative Che-1 expression was normalized with respect to hypoxanthine-guanine phosphoribosyltransferase (Hprt-1) expression. Human CHE-1 and p21 expressions were analyzed using SYBR Green Supermix (Bio-Rad) and normalized to HPRT-1 expression. TaqMan gene expression assay IDs for each set of primers and probe were: Che-1, Mm00498160_m1; Hprt1, Mm00446968_m1. The sequences of the primer used in SYBR Green assay were: CHE-1 forward, GCTGCTGAGGAACAGGAGTGT; $C H E-1$ reverse, ACTGAAGCCCGGTGTTTTTG; $p 21$ forward, AGACCAGCATGACAGATTTC; p21 reverse, ACTGAGACTAAGGCAGAAGA; HPRT-1 forward, TTGGAAAGGGTGTTTATTCCTCA; HPRT-1 reverse, TCCAGCAGGTCAGCAAAGAA. To evaluate the PCR efficiency for each set of primers, a standard curve was generated using serial dilutions (from 50 to $6.5 \mathrm{ng}$ ) of cDNA obtained from control cells. The efficiency was $90-100 \%$ for all the primers used. The amplification reaction was performed in duplicate for each sample in 96-well plates. The amount of Che-1 mRNA was calculated adopting the delta-delta-Ct method.

\section{Chromatin Immunoprecipitation (ChIP)}

ChIP experiments were performed as previously described (Zampieri et al., 2009). Immunoprecipitation with normal rabbit total IgG was performed as negative control. PCR amplification was performed using the following p21 promoter-specific primers (Bruno et al., 2006): forward, TCCGGGACCGGCTGGCCT; reverse, GCTCGGCCCACCGCGCCG. Reaction conditions were tested for signal linearity using increasing amounts of DNA template. 


\section{Immunofluorescence and Confocal Laser Scanner Microscopy}

Cells were seeded onto sterile glass coverslips. After 3 days, cells were treated with the indicated drugs and washed twice with PBS. For PAR immunofluorescence cells were fixed in $2 \%$ formaldehyde and permeabilized with $0.25 \%$ Triton $\mathrm{X}-100$ for $5 \mathrm{~min}$ at room temperature. For PARP-1 and Che-1 double immunofluorescence, cells were fixed in methanol:aceton $(1: 1 \mathrm{v} / \mathrm{v})$ for $10 \mathrm{~min}$ at $4^{\circ} \mathrm{C}$, dried, washed with PBS with $0.1 \%$ Tween 20 and blocked with $3 \%$ PBS-BSA for $30 \mathrm{~min}$ at room temperature. In both cases, coverslips were incubated at $4^{\circ} \mathrm{C}$ overnight with the specific antibodies (anti-PAR: clone 10HA, Trevigen; anti-PARP: clone F1-23, Alexis; anti-Che: rabbit polyclonal) and, after extensive washes with PBS, stained for $1 \mathrm{hr}$ at room temperature with fluorescein-conjugate donkey anti-mouse and rhodamine-conjugated donkey anti-rabbit secondary antibodies (Jackson ImmunoResearch). After extensive washing with PBS, coverslips were mounted on microscope slides with glycerol/PBS ( $\mathrm{pH}$ 9). Samples were analyzed using a Leica confocal laser scanning microscope (Laser Scanning TCS SP2) equipped with $\mathrm{Ar} / \mathrm{ArKr}$ and $\mathrm{HeNe}$ lasers. Laser line was at $488 \mathrm{~nm}$ for excitation FITC and 543 for excitation TRITC. The images were scanned under a 40 oil immersion objective. Optical spatial series were performed with a step size of $1 \mu \mathrm{m}$.

\section{Transfections}

For PARP-1 silencing, cells were transfected with siRNA (Dharmacon) at a final concentration of $50 \mathrm{nM}$ using INTERFERin ${ }^{\mathrm{TM}}$ transfection reagent (Polyplus Transfection) following manufacturer's instructions. Overexpressions of empty Myc vector and Myc-Che-1 vector were carried out using jetPEI ${ }^{\mathrm{TM}}$ transfection reagent (Polyplus Transfection) following manufacturer's instructions.

\section{Recombinant proteins and GST-pulldown assay}

BL21 E. coli strain was transformed with pGEX4T3 vector (Pharmacia) or GST-Che-1 vector [25] and the proteins were purified on glutathione-Sepharose resin (GE Healthcare). For GSTpulldown assay, comparable amounts of resin-bound GST-tagged proteins were incubated with high purity human recombinant PARP-1 (Alexis) or PARP-1 automodification domain (AD) (Alexis) in NETN buffer (20 mM Tris-HCl, $\mathrm{pH} 8.0,100 \mathrm{mM} \mathrm{NaCl}, 1 \mathrm{mM}$ EDTA, 0.5\% 
Nonidet P-40) for $2 \mathrm{hrs}$ at $4^{\circ} \mathrm{C}$. For GST-pulldown with automodified PARP-1, $500 \mathrm{ng}$ of recombinant PARP-1 were previously incubated for $2 \mathrm{hrs}$ at $30^{\circ} \mathrm{C}$ in poly(ADP-ribosyl)ation buffer (50 mM Tris-HCl, $\mathrm{pH} 8.0,10 \mathrm{mM} \mathrm{MgCl}_{2}, 1 \mathrm{mM}$ DTT) containing $0.1 \mu \mathrm{g}$ of DNase Iactivated DNA (Alexis) and $400 \mu \mathrm{M}$ NAD. After incubation the resins were pelleted and extensively washed in NETN buffer. The bound proteins were resuspended in SDS sample buffer and analyzed by $8 \%$ SDS-PAGE and Western blotting.

\section{Immunoprecipitation}

For Che-1 co-immunoprecipitation, nuclei were isolated from HCT116 cells in RSB buffer (10 mM HEPES, pH 7.9, $10 \mathrm{mM} \mathrm{KCl,} 1.5 \mathrm{mM} \mathrm{MgCl}_{2}, 0.5 \mathrm{mM}$ DTT, $50 \mathrm{mM} \mathrm{NaF}$ ) and lysed in buffer containing $20 \mathrm{mM}$ HEPES, $\mathrm{pH} 7.9,420 \mathrm{mM} \mathrm{NaCl}, 1.5 \mathrm{mM} \mathrm{MgCl} 2,0.2 \mathrm{mM}$ EDTA, $0.5 \mathrm{mM}$ DTT, 25\% glycerol. Nuclear extracts were diluited 1:3 in immunoprecipitation buffer (50 mM Tris-HCl, pH 7.4, $50 \mathrm{mM} \mathrm{NaCl}, 5 \mathrm{mM}$ EDTA, $10 \mathrm{mM} \mathrm{NaF}, 0.2 \% \mathrm{NP} 40$ ) and precleared with protein A-agarose beads (Upstate) on a rotative shaker at $4{ }^{\circ} \mathrm{C}$ for $2 \mathrm{hrs}$. Precleared lysates were incubated overnight at $4^{\circ} \mathrm{C}$ with anti-Che-1 antibody or with normal rabbit IgG (Santa Cruz Biotechnology) and then incubated $2 \mathrm{hrs}$ at $4^{\circ} \mathrm{C}$ with protein Aagarose beads. After extensive washing, immunoprecipitates were subjected to $8 \%$ SDSPAGE and Western blotting. For PAR immunoprecipitation, cell were directly collected in lysis buffer $\left(175 \mathrm{mM} \mathrm{KPO}_{4}, \mathrm{pH} 8.0,1 \%\right.$ NP40, $150 \mathrm{mM} \mathrm{NaCl}, 1 \mathrm{mM}$ DTT, $100 \mu \mathrm{M}$ ethacridine, protease inhibitors), mixed by inversion $1 \mathrm{hr}$ at $4{ }^{\circ} \mathrm{C}$ and centrifugated $10 \mathrm{~min}$ at $6000 \mathrm{~g}$ at $4^{\circ} \mathrm{C}$. NP40 concentration was adjusted to $0.5 \%$ and cell extracts were pre-cleared, incubated $2 \mathrm{hrs}$ at $4^{\circ} \mathrm{C}$ with anti-PAR antibody or normal mouse IgG (Santa Cruz Biotechnology) and $2 \mathrm{hrs}$ at $4^{\circ} \mathrm{C}$ with protein G-agarose beads (Upstate). Subsequently, beads were washed in $0.5 \%$ NP40 lysis buffer and analyzed by $8 \%$ SDS-PAGE and Western blotting. To detect in vivo poly(ADP-ribosyl)ation of Che-1, the buffer for PAR immunoprecipitation was modified to achieve $1 \% \mathrm{NP} 40$ and $1 \mathrm{M} \mathrm{NaCl}$ concentrations. AntiMyc immunoprecipitation was carried out as described above for PAR immunoprecipitation, but using a buffer containing $175 \mathrm{mM} \mathrm{KPO}_{4}, \mathrm{pH} 8.0,1 \% \mathrm{NP} 40,400 \mathrm{mM} \mathrm{NaCl}, 1 \mathrm{mM}$ DTT, $100 \mu \mathrm{M}$ ethacridine, protease inhibitors. 


\section{Polymer blot assay}

PAR were purified from PARP-1 automodified in vitro [27] in non-radioactive conditions. Polymer blot was performed as described [28]. Briefly, increasing amounts (5, 10 and 15 pmol) of GST, GST-Che-1, histone H1 (positive control) and DNase I (negative control) were dotted onto nitrocellulose membrane (Hybond ${ }^{\mathrm{TM}} \mathrm{ECL}^{\mathrm{TM}}$ GE Healthcare) using a dot blot apparatus (BioRad). The membrane was blocked overnight in 5\% nonfat dry milk in Trisbuffered saline (TBS, $10 \mathrm{mM}$ Tris, $0.15 \mathrm{M} \mathrm{NaCl}, \mathrm{pH}$ 7.4) plus $0.05 \%$ Tween 20 (TBST), washed and then incubated with $2 \mu \mathrm{g}$ of PAR diluted in $3 \mathrm{ml}$ of TBST. The membrane was extensively washed with TBST containing $0.5 \mathrm{M} \mathrm{NaCl}$ and subjected to immunodetection with anti-PAR antibody.

\section{In vitro poly(ADP-ribosyl)ation of recombinant Che-1}

The GST moiety was cleaved from recombinant GST-Che-1 by overnight incubation with thrombin (GE Healthcare). $1.0 \mu \mathrm{g}$ of recombinant Che-1 was pre-incubated $20 \mathrm{~min}$ at room temperature with high purity recombinant PARP-1 $(0.1 \mu \mathrm{g}$; Alexis) in reaction buffer (final volume $25 \mu \mathrm{l}$ ) containing $50 \mathrm{mM}$ Tris- $\mathrm{HCl}, \mathrm{pH} 8.0,5 \mathrm{mM} \mathrm{MgCl}_{2}$ and $1 \mathrm{mM}$ DTT. In the indicated sample $8 \mathrm{mM} 3$-ABA was added, and in all samples $0.15 \mu \mathrm{g}$ of DNase I treated DNA and $100 \mu \mathrm{M} \mathrm{NAD}^{+}$were added. The incubation was carried out for 20 and $30 \mathrm{~min}$ at $30^{\circ} \mathrm{C}$. The reaction was terminated by addition of SDS sample buffer and boiling of the samples. Proteins were separated by $8 \%$ SDS-PAGE and subjected to anti-PAR and anti-Che1 immunodetection. 


\section{RESULTS}

\section{Effect of doxorubicin treatment on PARP activity}

To evaluate PARP response induced by Doxo, PARP activity was measured by immunofluorescence and immunoblotting analysis. Human colon carcinoma HCT116 cells were treated with Doxo $1 \mu \mathrm{M}$ for $4 \mathrm{hrs}$ and PARP activity was evaluated by indirect immunofluorescence against PAR. A significant increase in PAR level was observed in the nuclei of Doxo treated cells with respect to control cells (Figure 11A). HCT116 cells were then treated with Doxo at different times up to $8 \mathrm{hrs}$. At the indicated times this Doxo concentration produced a non-apoptotic damage as previously evidenced by FACS analysis showing a sub-G1 peak less than 8\% (De Nicola et al., 2007). Immunoblotting analysis showed a clear increase in PAR level detectable as early as $30 \mathrm{~min}$ after the treatment and which persisted up until $8 \mathrm{hrs}$ in the presence of the drug (Figure 11B). As expected, Doxo treatment caused an increase in Che-1 protein level in a time-dependent manner (Figure 11B) due to Che-1 stabilization (Bruno et al., 2006). PARP-1 did not exhibit any cleavage, consistent with the exposure of the cells to a non-apoptotic damage.

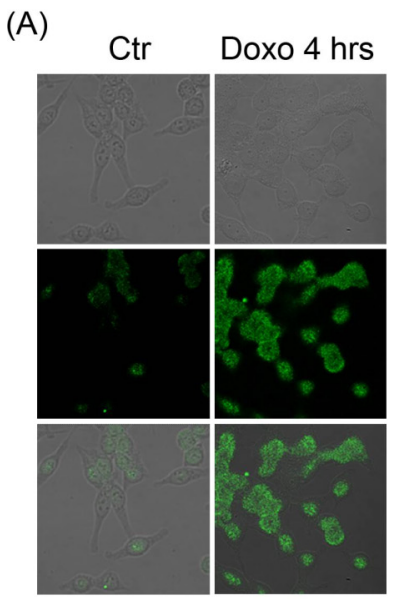

(B)

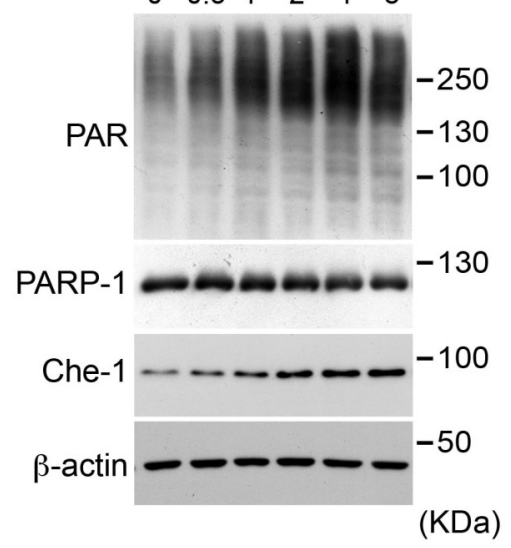

Figure 11. Effect of Doxo treatment on PAR synthesis. (A) Immunofluorescence analysis of PAR level in HCT116 control cells and after $4 \mathrm{hrs}$ of $1 \mu \mathrm{M}$ Doxo treatment. Nuclei are visible in bright field images. Overlaid images show that Doxo induces PAR formation in nuclei. (B) Time course of PAR formation in HCT116 cells after $1 \mu \mathrm{M}$ Doxo treatment. Western blotting was performed on total cell extracts using the indicated antibodies. 


\section{PARP-1 activity is required for efficient Che-1 accumulation in doxorubicin treated cells}

The role of poly(ADP-ribosyl)ation in the process leading to Che-1 accumulation was investigated using two different PARP inhibitors: 3-aminobenzamide (3-ABA) and PJ-34. HCT116 cells were pre-treated with $8 \mathrm{mM} 3$-ABA $30 \mathrm{~min}$ before Doxo treatment and the inhibitor was maintained in the medium during the course of the damage ( $4 \mathrm{hrs}$ ). Treatment of cells with 3-ABA (Figure 12A) caused a clear inhibition of PAR synthesis both in Doxountreated and Doxo-treated cells. Notably, we observed a significant reduction of Che-1 accumulation in cells co-treated with 3-ABA and Doxo with respect to cells treated with Doxo alone (Figure 12A, B). According to Haince et al. (2007), PARP activity inhibition also decreased phosphorylation of the ATM substrate H2AX (Figure 12A).

(A)

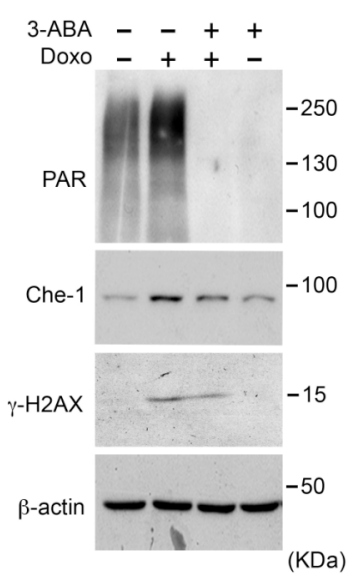

(B)

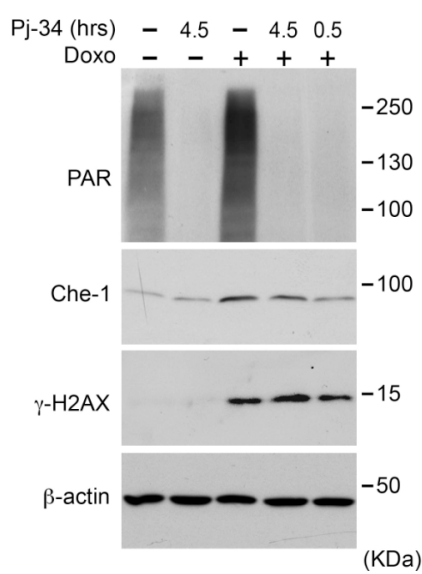

(C)

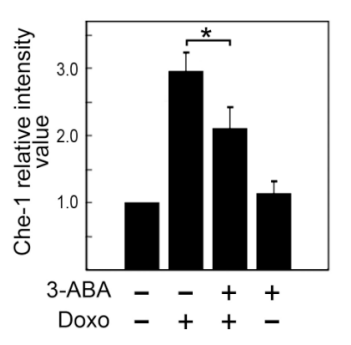

(D)

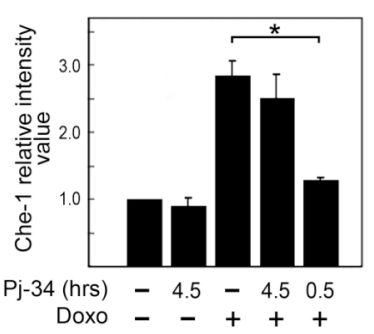

Figure 12. PARP inhibitors affect Che-1 stabilization upon Doxo treatment. (A) HCT116 cells were treated with Doxo for $4 \mathrm{hrs}$ in the presence or absence of $8 \mathrm{mM}$ 3-ABA (30 min pre-treatment) and analyzed by Western blotting using antibodies against PAR, PARP-1 (C2-10 clone), Che-1, $\gamma$-H2AX and $\beta$ actin. (B) HCT116 cells were exposed to $1 \mu \mathrm{M}$ Doxo for 4 hrs and co-treated with $5 \mu \mathrm{M}$ PJ-34 as indicated: 4.5 hrs corresponds to a 30 min pre-treatment with the inhibitor, while $0.5 \mathrm{hrs}$ indicates that PJ-34 was added in the last $30 \mathrm{~min}$ of the $4 \mathrm{hrs}$ Doxo treatment. Cell extracts were analyzed by Western blotting using antibodies against. (C) and (D) Densitometric analysis of Che-1 signals in three independent experiments performed respectively as in (A) and (B). Che-1 protein levels were normalized with $\beta$-actin and indicated as ratio with respect to control cells. The asterisks indicate a significant difference ( $p$-value $<0.05)$ in Che-1 levels between the compared samples. 
However, when we performed the same experiment pre-treating the cells with the second generation inhibitor PJ-34 (Figure 12C, D), we could not detect a significant impairment in Doxo-induced Che-1 accumulation. Conversely, we observed a significant reduction in Che-1 stabilization when PJ-34 was added in the last $30 \mathrm{~min}$ of the $4 \mathrm{hrs}$ Doxo treatment. It is likely that prolonged co-treatment (4 hrs) with Doxo and the powerful inhibitor PJ-34 promoted the accumulation of unrepaired DNA lesions, and as a consequence did not allow the reduction in Che-1 levels which is detectable after shorter exposure to PJ-34 and upon 3-ABA pretreatment.

Consistent with this, cells exposed to Doxo and PJ-34 for $4 \mathrm{hrs}$ did not exhibited a decrease, but a slight increase in phosphorylation of H2AX (Figure 12B). Since our aim was to analyze the role of poly(ADP-ribosyl)ation reactions in the first phases of DDR, in the subsequent experiments we decided to use 3-ABA as a PARP inhibitor, because it did not induce an increase in DNA damage level when used in combination with Doxo.

PARP-1+/+ and PARP-1-/- mouse embryonic fibroblasts (MEF) (Wang et al., 1995) were used to determine whether the absence of PARP-1 could affect Che-1 accumulation during Doxo treatment. In a time course of Doxo treatment up to $6 \mathrm{hrs}$ (Figure 13A), an increase in PAR level was detectable by immunoblot in PARP- $1^{+/+}$but not in PARP- $1^{-/-}$MEF. Notably in response to DNA damage, knock-out cells exhibited only a partial increase in Che-1 levels with respect to wild type cells (Figure 13A, C). Furthermore, when PARP-1 expression was transiently down-regulated by RNA interference in HCT116 cells, we observed a significant impairment in Che-1 accumulation following Doxo treatment (Figure 13B, D).

No alterations in Che-1 mRNA levels were observed following Doxo treatment and in 3-ABA inhibited or PARP-1 knock-out cells (Figure 14), confirming a post-translational regulation over Che-1 accumulation (Bruno et al., 2006). 
(A)

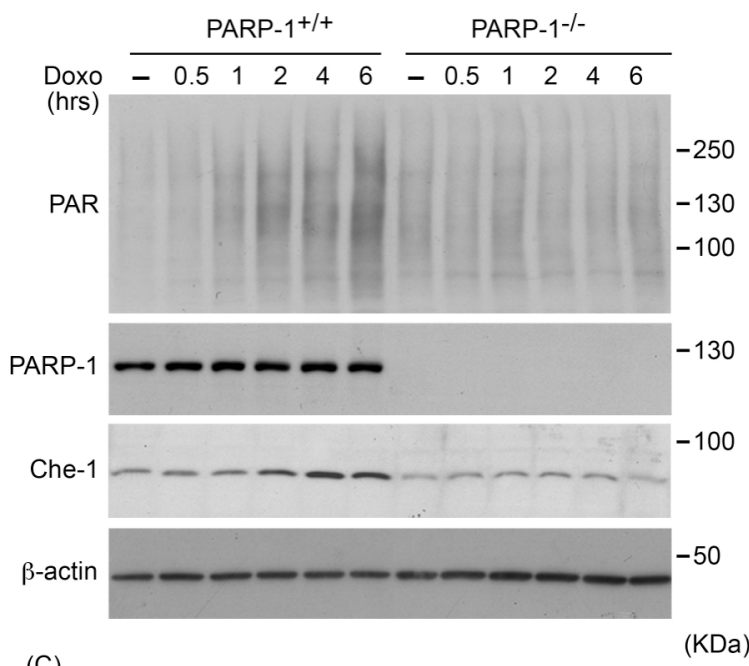

(C)

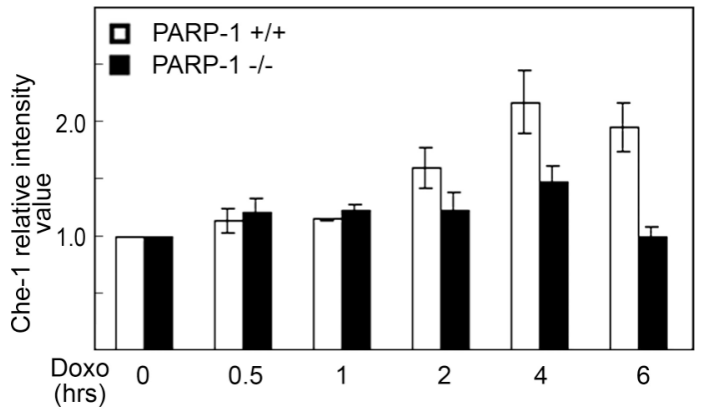

(B)

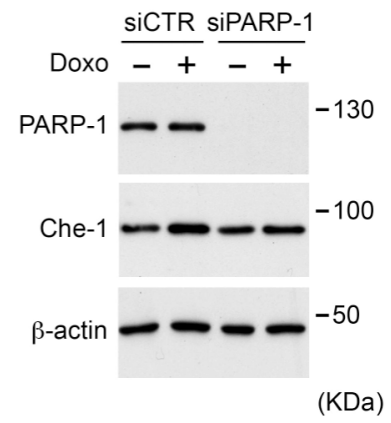

(D)

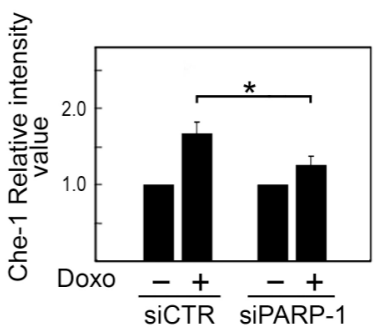

Figure 13. PARP-1 activity is required for efficient Che-1 accumulation in Doxo treated cells. (A) PARP- $1^{+/+}$and PARP- $1^{-/}$MEF were exposed to $1 \mu \mathrm{M}$ Doxo for the indicated times and analyzed by Western blotting. (B) HCT116 cells were transfected with control siRNA or PARP-1 specific siRNA, treated with $1 \mu \mathrm{M}$ Doxo for $4 \mathrm{hrs}$ and analyzed by Western blotting. (C) and (D) Densitometric analysis of Che-1 signals in three independent experiments performed respectively as in (A) and (B). Che-1 protein levels were normalized with $\beta$-actin and indicated as ratio with respect to control cells. The asterisk in (D) indicates a significant difference ( $p$-value $<0.05)$ in Che-1 levels between the compared samples. 
(A)

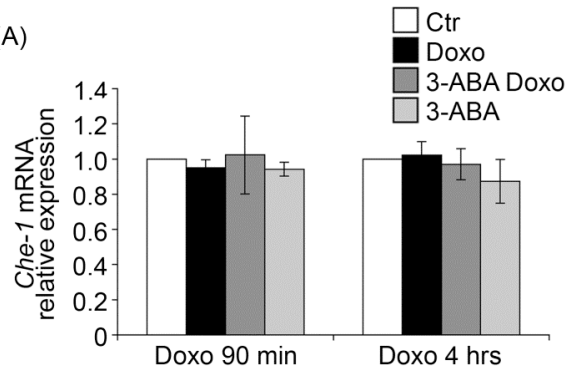

(B)

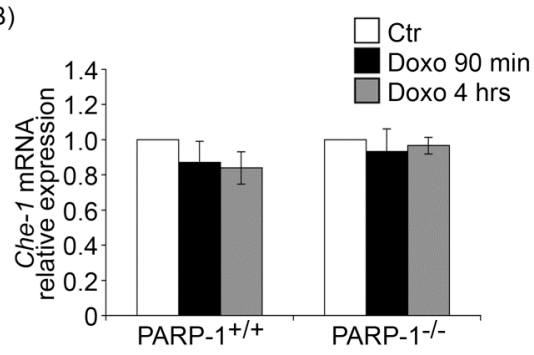

Figure 14. Che-1 mRNA level is not affected by Doxo and 3-ABA treatment. (A) Real-time RT-PCR measurements of Che-1 mRNA levels in PARP-1 ${ }^{+/+}$and PARP- $1^{-/ 2}$ MEF exposed to Doxo for 90 min and 4 hrs. The graphs represent Che-1 mRNA levels normalized to Hprtl mRNA. The mRNA level in untreated cells is considered as 1.0. The results are expressed as mean \pm S.D. of three independent experiments. (B) Realtime RT-PCR measurements of CHE-1 mRNA levels in HCT116 cells exposed to Doxo for 4 hrs in presence or absence of 3-ABA. The graphs depict CHE-1 mRNA levels normalized to HPRT-1mRNA.

\section{3-aminobenzamide treatment of doxorubicin-exposed HCT116 cells reduces Che-1 recruitment on $p 21$ promoter and impairs $p 21$ transcription}

Che-1 has an established role as a transcriptional activator (Page et al., 1999) and previous results showed that upon DNA damage Che-1 physically associates with the $p 21$ promoter and stimulates the expression of the corresponding gene (Bruno et al., 2006). Since it has been reported that PARP inhibition attenuates $p 21$ expression after IR exposure (Wieler et al., 2003), we asked whether the reduction in Doxo-induced Che-1 accumulation upon 3-ABA treatment could play a role in the modulation of $p 21$ expression.

As shown in Figure 15A, chromatin immunoprecipitation (ChIP) experiments confirmed Che1 recruitment on $p 21$ promoter in Doxo-treated cells. The presence of Che-1 at the $p 21$ promoter was reduced following pre-treatment of Doxo-exposed cells with 3-ABA and this depletion was consistent with an impairment in Che-1 stabilization upon PARP inhibition. According to this finding, real-time PCR analysis showed that the increase in $p 21$ expression in cells exposed to Doxo was significantly reduced by pre-treatment with 3-ABA (Figure 15B). 
(A)

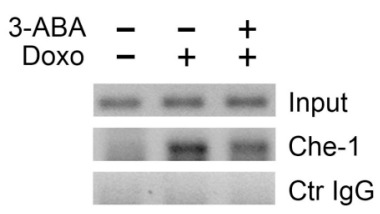

(B)

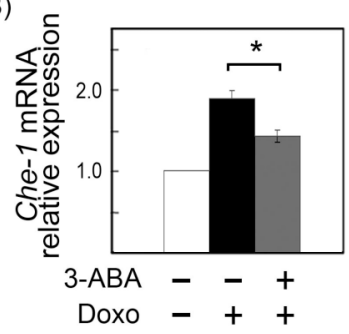

Figure 15. Inhibition of PARP activity impairs Che-1 recrutiment on $p 21$ promoter and reduces its transcription. (A) HCT116 cells were treated with $1 \mu \mathrm{M}$ Doxo for 4 hrs with or without $8 \mathrm{mM}$ 3-ABA (30 min pre-treatment) and subjected to ChIP using anti-Che-1 antibody. Immunoprecipitates from each sample were analyzed by PCR using primers specific for $p 21$ promoter. For each sample, amplification was performed on total input chromatin (Input) and on ChIP products achieved using normal rabbit IgG as antibody (Ctr IgG). (B) Real-time RT-PCR measurements of $p 21$ mRNA levels in HCT116 cells exposed to $1 \mu \mathrm{M}$ Doxo for $4 \mathrm{hrs}$ in presence or absence of $8 \mathrm{mM} 3-\mathrm{ABA}$. The graphs represent $p 21 \mathrm{mRNA}$ levels normalized to HPRT-1 mRNA.

\section{PARP activity cooperates with ATM kinase activity to stabilize Che-1}

PARP-1 has been shown to be important for activation of ATM signalling pathway (Haince et al., 2007). Taking into account that Che-1 is an ATM substrate, we performed epistasis experiments to investigate whether the effect of PARP activity on Che-1 accumulation was mediated by ATM.

Inhibition of ATM with KU55933 (Figure 16A) reduced Doxo-induced stabilization of Che-1 in HCT116 cells. The effect of PARP inhibition on Che-1 stabilization was evident also in ATM inhibited cells, and an almost complete decrease in Che-1 accumulation was achieved when 3-ABA was used in combination with KU55933 (Figure 16A, C).

We then compared the effects of Doxo and 3-ABA treatments on Che-1 accumulation in human fibroblasts ATM-proficient or derived from ataxia teleangiectasia patients (A-T fibroblasts) (Figure 16B, D). Although less consistent than in ATM-proficient cells, an increase in Che-1 level upon Doxo treatment was evident also in A-T fibroblasts. While in ATM proficient fibroblasts 3-ABA caused a reduction in Doxo-induced Che-1 levels comparable to that one achieved in HCT116 cells, in A-T fibroblasts it promoted an almost complete abrogation of Che-1 stabilization. 
Overall these results indicate that the effect of poly(ADP-ribosyl)ation on Che-1 stabilization is, at least in part, independent of ATM.
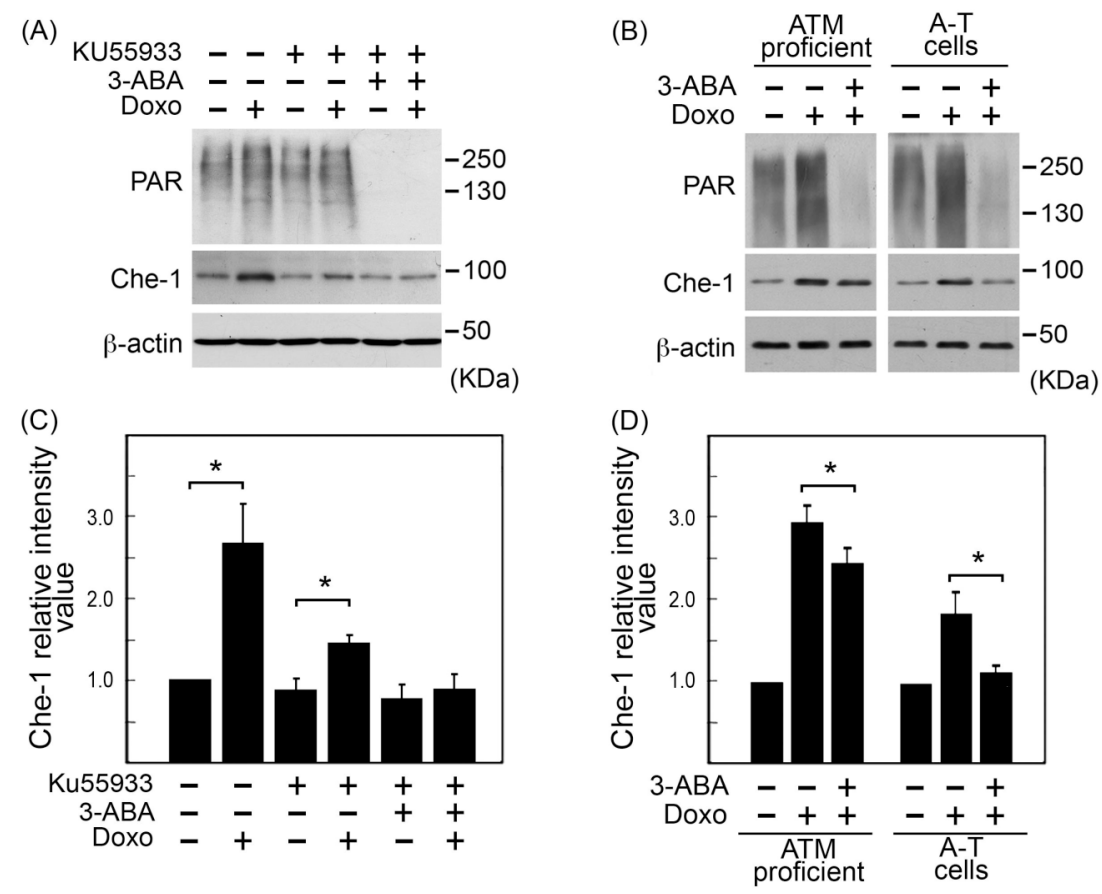

Figure 16. Inhibition of PARP activity impairs Che-1 stabilization in a way independent from ATM. (A) HCT116 cells were exposed to $4 \mathrm{hrs} 1 \mu \mathrm{M}$ Doxo treatment after 30 min pre-treatment with $10 \mu \mathrm{M}$ KU55933 alone or in combination with $8 \mathrm{mM} 3$-ABA. Western blotting analysis on cell extracts is reported. (B) ATM proficient and A-T fibroblasts were exposed to $1 \mu \mathrm{M}$ Doxo treatment for $4 \mathrm{hrs}$ in presence or absence of $8 \mathrm{mM} 3-\mathrm{ABA}$ added $30 \mathrm{~min}$ prior to damage. Total cell extracts were analyzed by Western blotting. (C) and (D) Densitometric analysis of Che-1 signal in three independent experiments performed as in (A) and (B). The signal was normalized with $\beta$-actin and indicated as ratio with respect to control cells. The asterisks indicate a significant difference $(p$-value $<0.05)$ in Che-1 levels between the compared samples. 


\section{Che-1 co-immunoprecipitates with ADP-ribose polymers but it does not bind them non- covalently}

To further explore the mechanism by which PARP inhibition reduces Che- 1 accumulation in response to Doxo, we verified whether PAR could directly interact with Che-1 protein.

HCT116 total cell extracts from control and Doxo-treated cells at 30 and 90 min were immunoprecipitated with anti-PAR antibody as indicated in Figure 17A. The PARG inhibitor ethacridine (Tavassoli et al., 1985) was used in all the experimental steps to avoid PAR degradation. Che-1 co-immunoprecipitated with PAR in control cells and this interaction rapidly strengthened upon Doxo-treatment.

Che-1 aminoacidic sequence does not harbour a consensus motif for non-covalent interaction with PAR. However since some proteins, like histone H1, can bind PAR also in absence of a canonical PAR-interaction motif, we performed a polymer blot assay. Increasing amounts (5, 10 and 15 pmol) of GST and GST-Che- 1 recombinant proteins were dotted onto the same nitrocellulose membrane together with the positive control $\mathrm{H} 1$ and the negative control DNase I. The filter was incubated with free PAR for $1 \mathrm{hr}$ and PAR bound to proteins were detected by anti-PAR antibody. Figure $17 \mathrm{~B}$ shows no significant dot blot signal for polymer binding to GST and GST-Che-1, whereas histone H1 shows a signal decreasing linearly with the amount of protein. These results exclude a non-covalent interaction of Che-1 with PAR, pointing to the possible covalent poly(ADP-ribosyl)ation of Che-1.

\section{Che-1 interacts with PARP-1 in vivo and in vitro}

To test whether PARP-1 was involved in Che-1 accumulation through its direct modification, we performed a series of experiments to assess the physical interaction between Che-1 and PARP-1.

We examined the subcellular localization of PARP-1 and Che-1 by immunofluorescence and confocal microscopy analysis (Figure 18A). In control cells a strong nucleolar colocalization of Che-1 and PARP-1 was observed. Upon exposure of cells to 4 hrs of Doxo treatment, delocalization of the two proteins from nucleoli to nucleoplasm occurred. PARP-1 was found especially at the periphery of nuclei and Che-1 was mainly distributed throughout the nucleus. 
(A)

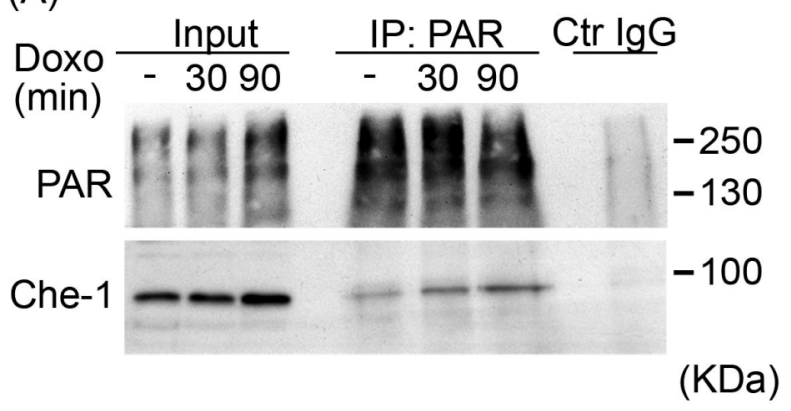

(B)

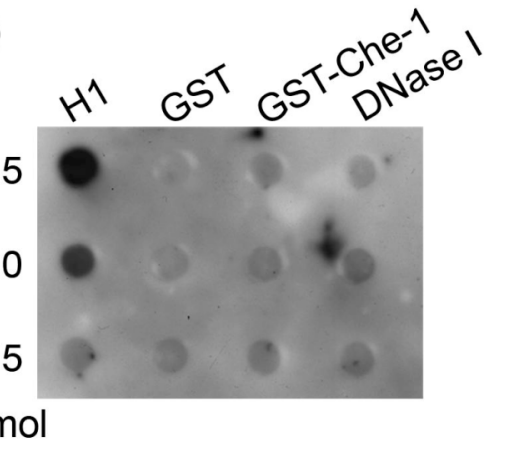

Figure 17. Che-1 co-immunoprecipitates with PAR but does not interact with them noncovalently. (A) Total cell extracts from HCT116 cells untreated or treated with $1 \mu \mathrm{M}$ Doxo at 30 and 90 min were immunoprecipitated with anti-PAR antibody and analyzed by Western blotting with anti-PAR and antiChe-1 antibodies. Input corresponds to $5 \%$ of the total cellular extract used for immunoprecipitation. Ctr IgG indicates immunoprecipitation carried out with control normal mouse IgG. (B) Polymer blot assay to analyze the in vitro PAR binding affinity of different proteins. GST, GST-Che-1, histone H1 and DNAase I recombinant proteins were spotted onto nitrocellulose membrane in the indicated amount and incubated with free PAR. Protein-bound polymers were evidenced using anti-PAR antibody.

However, we still observed association between Che-1 and PARP-1 after DNA damage, evidenced by the persistence of foci of co-localization detected in the merge analysis.

Co-immunoprecipitation on nuclear extracts with anti-Che-1 antibody confirmed that Che-1 binds PARP-1 both in HCT116 control and Doxo-treated cells (Figure 18B). This interaction appeared to be stimulated upon Doxo treatment, but we could not exclude that this increase was caused by the higher level of Che- 1 in damaged cells.

Next GST-pulldown experiments were performed to evaluate whether the observed association between PARP-1 and Che-1 was direct. GST and GST-Che-1 were incubated with human recombinant PARP-1 (Figure 18C, upper panel) or with the automodification domain (AD) of the enzyme (Figure 18C, middle panel). Western blotting analysis showed that GSTChe-1 specifically binds PARP-1 and in particular that it can interact with its AD. Unless the existence of a non-covalent binding, high levels of PAR on the automodification domain 
(A)
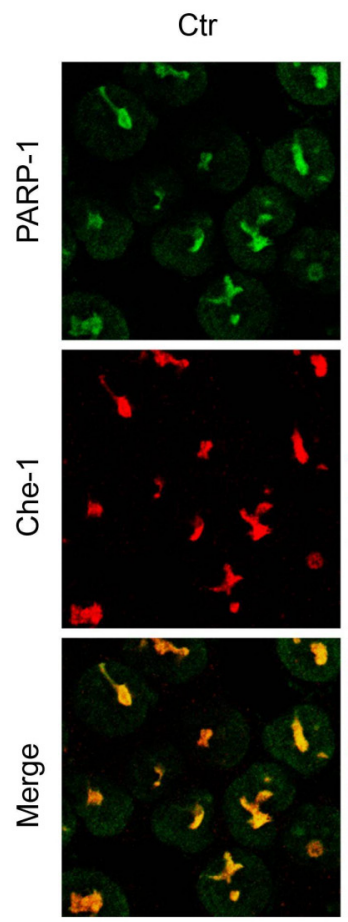

Doxo 4 hrs
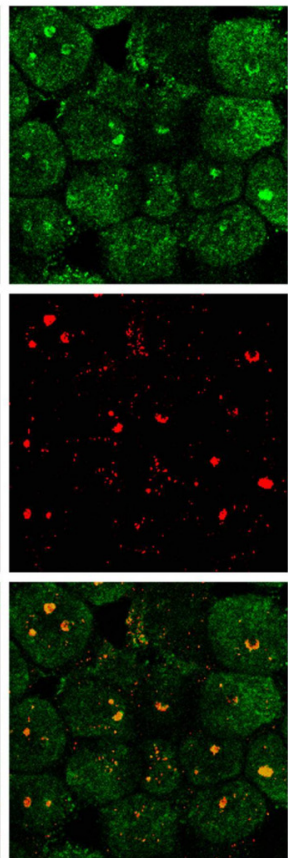

(B)

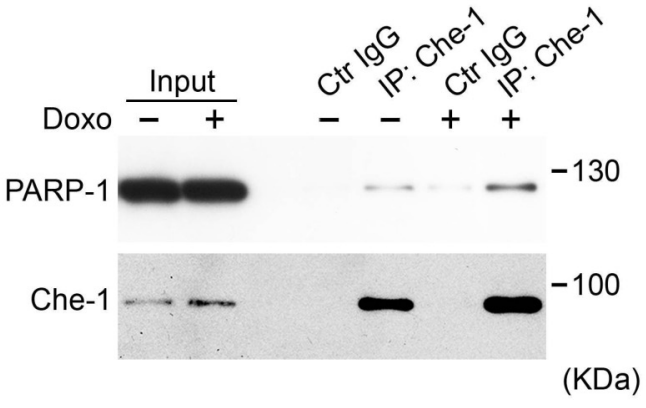

(C)

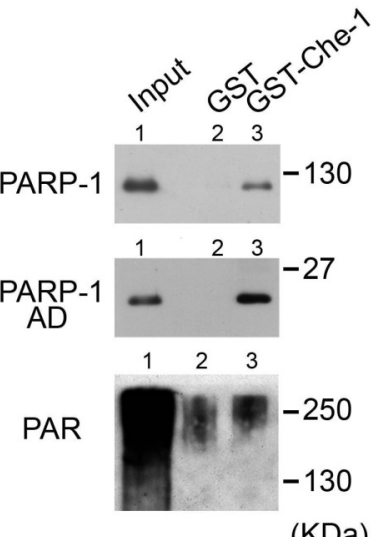

Figure 18. Che-1 physically interacts with PARP-1. (A) Nuclear co-localization of PARP-1 and Che-1 assessed by immunofluorescence and confocal analyses. Yellow signal in lower panels corresponds to colocalization of PARP-1 (green signal) and Che-1 (red signal). The optical sections shown are recovered at nuclear level. (B) Nuclear extracts from HCT116 cells treated or not with $1 \mu \mathrm{M}$ Doxo for $4 \mathrm{hrs}$ were immunoprecipitated with anti-Che-1 antibody and analyzed by Western blotting with anti-PARP-1 (C2-10 clone) and anti-Che-1 antibodies. Input corresponds to $5 \%$ of nuclear extract used for immunoprecipitation. Ctr IgG indicates immunoprecipitation carried out with control normal rabbit IgG. (C) GST and GST-Che-1 proteins were incubated with human recombinant PARP-1 (upper panel), with the automodification domain (AD) of PARP-1 (middle panel) or with in vitro automodified PARP-1 (lower panel) and subjected to GST-pulldown. The input represents $10 \%$ of the total incubate. In Western blotting, full length recombinant PARP-1 was detected by the C2-10 monoclonal antibody, AD domain of PARP-1 was detected by anti-PARP-1 polyclonal antibody and automodified PARP-1 was detected using anti-PAR antibody. 
should decrease the interaction between PARP-1 and proteins. GST and GST-Che-1 were incubated with recombinant PARP-1 previously automodified in presence of DNase I activated DNA and NAD (Figure 17C, lower panel). We used anti-PAR antibody to detect automodified PARP-1 as a high molecular smear. As expected, no significant increase in signal was detected in the GST-Che-1 pulldown sample with respect to the negative control GST (lane 3 vs lane 2).

Altogether these results indicate that Che-1 directly interacts with PARP-1 and is therefore a possible substrate of the catalytic activity of the enzyme.

\section{Che-1 is poly(ADP-ribosyl)ated by PARP-1 in vitro and in vivo}

We examined whether PARP-1 could modify Che-1 in vitro in a reconstituted poly(ADPribosyl)ating enzyme system. Che-1 was detached from the resin upon overnight cleavage of the GST moiety with thrombin. Reaction conditions were optimized for heteromodification. Recombinant Che-1 and PARP-1 were pre-incubated for $15 \mathrm{~min}$ at room temperature, then added of NAD and nicked DNA and incubated at $30^{\circ} \mathrm{C}$ for 20 and $30 \mathrm{~min}$. The reaction products were analyzed by immunoblotting with anti-PAR antibody (Figure 19A). Automodification of PARP-1 at 20 and 30 min was detected as a high molecular weight smear (lanes 1,2). In the presence of recombinant Che-1 (lanes 3, 4), the smear started from a lower molecular weight which coincided with Che-1 electrophoretic position, as revealed by reprobing the filter with anti-Che-1 antibody. No PAR signal was detected when Che-1 and PARP-1 were incubated under the same experimental conditions but in presence of 3-ABA (lane 5). These results indicate that in vitro Che-1 is a substrate of PARP-1 activity.

We used different approaches to verify the existence of in vivo poly(ADP-ribosyl)ation of Che-1. First of all we immunoprecipitated PAR in highly stringent conditions in order to select covalently modified proteins and avoid non-covalent interactions with PAR (Figure 19B). In these conditions we still observed co-immunoprecipitation of Che-1, indicating a covalent poly(ADP-ribosyl)ation of the protein.

To confirm this data, HCT116 cells were transfected with empty Myc vector or Myc-Che-1 vector and after $24 \mathrm{hrs}$ were treated with Doxo for $4 \mathrm{hrs}$. Total cell extracts were immunoprecipitated with anti-Myc antibody in stringent conditions (Figure 19C). Immunoblot with anti-PAR showed a specific signal overlapping with Myc-Che-1 
electrophoretic position, confirming the existence of a poly(ADP-ribosyl)ated form of Che-1 in Doxo-exposed cells.

(A)

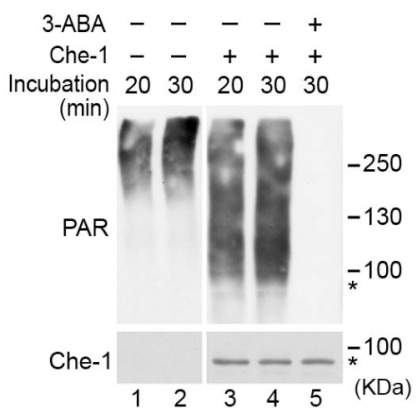

(B)

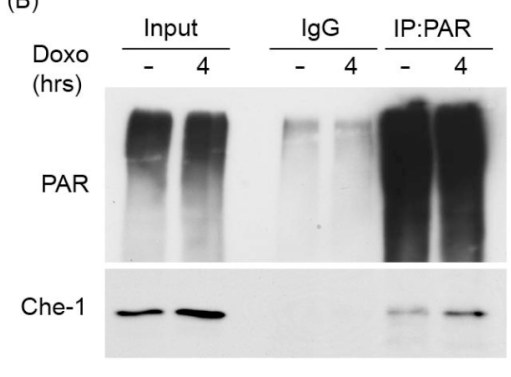

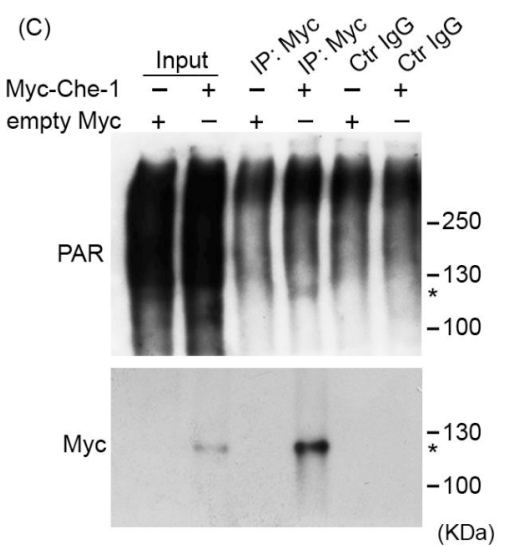

Figure 19. Che-1 is modified by PARP-1 in vitro and in vivo. (A) In vitro poly(ADP-ribosyl)ation of Che-1. Recombinant PARP-1 $(0.1 \mu \mathrm{g})$ was incubated in poly(ADP-ribosyl)ation buffer for 20 and $30 \mathrm{~min}$ (lanes 1, 2) alone or in presence of $1.0 \mu \mathrm{g}$ of recombinant Che-1 (lanes 3, 4). Addition of 3-ABA to the samples abolished the modification reaction (lane 5). The reaction mixtures were subjected to 8\% SDS-PAGE and immunoblotted with anti-PAR antibody (top panel). The membrane was stripped and reprobed with anti-Che-1 antibody (lower panel). (B) Total cell extracts from HCT116 cells untreated or treated with $1 \mu \mathrm{M}$ Doxo for $4 \mathrm{hrs}$ were immunoprecipitated with anti-PAR antibody in highly stringent conditions ( $1 \% \mathrm{NP}-40,1 \mathrm{M} \mathrm{NaCl})$ and analyzed by Western blotting with anti-PAR and anti-Che-1 antibodies. Ctr $\operatorname{IgG}$ corresponds to immunoprecipitation carried out with control normal mouse IgG. (C) HCT116 cells were transfected with Myc empty vector or with Myc-Che-1 expression vector. After $24 \mathrm{hrs}$ of transfection, cells were treated with $1 \mu \mathrm{M}$ Doxo for 4 hrs and total cells extracts were immunoprecipitated with anti-Myc and analyzed by Western blotting with the indicated antibodies. Asterisks indicate the positions of poly(ADP-ribosyl)ated Che-1. 


\section{DISCUSSION}

Among the various post-translational modifications, poly(ADP-ribosyl)ation is assuming a central role in coordinating cell response to stress stimuli. In this work we have explored the involvement of PARP activity in DNA damage-induced signalling cascade, showing that poly(ADP-ribosyl)ation positively regulates the stabilization of Che-1 protein.

We demonstrated that Che- 1 accumulation induced by 4 hrs Doxo treatment is significantly reduced following inhibition of PARP activity (Figure 12). In particular, impairment in Che-1 stabilization was observed after pre-treatment with 3-ABA and after short co-treatment with the more powerful inhibitor PJ-34, but not after pre-treatment with PJ-34 and its prolonged combination with Doxo (4 hours). Although PARP inhibitors are a useful tool to analyze the role of poly(ADP-ribosyl)ation reactions in the DDR, it is well established that, when used in combination with DNA damaging agents, they can induce an increase in the level of DNA damage and further activate DDR. In fact, PARP inhibitors can prevent the release of the enzyme from DNA lesions, a necessary event for the completion of the repair, and therefore induce DNA damage by triggering the stalling of replication forks (Aguilar-Quesada et al., 2007; Carrozza et al., 2009; Horton et al., 2005). Consistent with this, pre-treatment of Doxoexposed cells with PJ-34 led to an increase in DNA damage level, which probably promoted Che-1 stabilization through alternative pathways independent from inhibition of PARP activity. This effect was not observed with the less powerful inhibitor 3-ABA, which therefore appeared to be a better means to analyze the role of poly(ADP-ribosyl)ation in the first phases of the transduction cascade that regulates the adaptative response of the cell to DNA damage. Importantly, we showed that Doxo-induced stabilization of Che-1 was significantly impaired in PARP-1 knock-out and silenced cells (Figure 13), indicating that PARP-1 is the PARP enzyme involved in Che-1 accumulation.

Previous reports indicate that inhibition of PARP activity reduces transcription of $p 21$ upon DNA damage (Wieler et al., 2003) by both p53-independent and p53-dependent mechanisms (Madison and Lundblad, 2010). Here we demonstrated that impairment in Che-1 accumulation by PARP inhibition reduced Che-1 occupancy at $p 21$ promoter and affected the expression of the corresponding gene (Figure 14), indicating a role of PARP activity in the regulation of Che-1 function in DDR. Notably the Che-1 binding site resides in the proximal 350 nucleotides of $p 21$ promoter, a region which contains a p53-independent and PARPsensitive control element (Madison and Lundblad, 2010). Based on the function of Che-1 in 
G2/M checkpoint, our data suggest that PARP-1 contributes to the cell cycle arrest upon Doxo treatment.

Poly(ADP-ribosyl)ation modulates ATM phosphorylation cascade in the immediate response to DDR (Haince et al., 2007). Che-1 stabilization is regulated by ATM and ATR kinases, and inhibition of their activities partially reduces Che-1 accumulation upon Doxo treatment (Bruno et al., 2006). PARP-1 might therefore exert its effect on Che-1 accumulation in two ways not necessarily mutually exclusive: i) by acting upstream of ATM kinase; ii) by acting through a parallel pathway independent from ATM. To distinguish between these two hypotheses we performed epistasis experiments and analyzed the effect of the simultaneous impairment of PARP and ATM activities on Che-1 level after DNA damage (Figure 16). If PARP-1 acted exclusively upstream of ATM, PARP inhibition should not have a further effect on Che-1 stabilization respect to ATM inhibition or ATM impairment in A-T cells. On the contrary our results clearly indicate that phosphorylation by ATM and poly(ADPribosyl)ation act in independent pathways to modulate Che-1 stabilization.

In the effort to understand how poly(ADP-ribosyl)ation takes part in Che-1 stabilization, immunoprecipitation with anti-PAR antibody was performed. The amount of Che-1 coimmunoprecipitated with PAR increased as soon as 30 min post Doxo treatment, when the total level of Che-1 in the cells was not yet raised (Figure 17). This result suggests a rapid association of Che-1 with PAR following DNA damage. Since this association was not due to a non-covalent interaction of Che- 1 with PAR (Figure 17) and considering that Che-1 is a highly acidic protein rich in glutammic and aspartic acid residues, which are preferential substrates of PARP catalytic activity, we investigated whether Che-1 could be modified by PARP-1. Here we showed that Che-1 directly interacts with PARP-1 (Figure 18) and that Che-1 is poly(ADP-ribosyl)ated by PARP-1 (Figure 19).

The direct interaction was verified by different approaches (Figure 18). Immunofluorescence analysis showed a high level of co-localization of PARP-1 and Che-1 in nucleoli of non treated cells, in agreement with previous data concerning a nucleolar distribution of PARP-1 (Meder et al., 2005; Rancourt and Satoh, 2009) and Che-1 (Andersen et al., 2005). The functional implication of this interaction in unstimulated cells is not known, but it could be correlated to the role of the two proteins in transcription regulation (Bruno et al., 2002; Kraus and Lis, 2003). As reported also for other nucleolar proteins (Dellaire and Bazett-Jones, 2007), delocalization of the two proteins from nucleoli to nucleoplasm occurred upon exposure to stress stimuli, although some foci of co-localization of Che-1 and PARP-1 were still detectable. Immunoprecipitation experiments confirmed this interaction both in control 
and in Doxo-exposed cells. In vitro Che-1 directly interacted with recombinant PARP-1 but failed to bind highly modified PARP-1, confirming the result of the polymer blot assay and excluding the existence of a non-covalent binding between PAR and Che-1. Based on these observations, we suggest that the interaction shown in our immunofluorescence and immunoprecipitation experiments in Doxo-exposed cells occurs between Che-1 and a pool of non-modified or low-modified PARP-1 molecules. Indeed, poly(ADP-ribosyl)ation of PARP1 upon DNA damage is an highly dynamic process, in which PARP-1 molecules shuttle between an high and a low level of modification because of PARG activity.

The interaction between the two proteins appears to be the prerequisite for the catalytic activity of PARP-1 on Che-1. Such as many other substrates of PARP-1 (Bauer et al., 2001; Hassa et al., 2001; Oei et al., 1997; Yung et al., 2004), Che-1 bound the automodification domain of PARP-1 (Figure 18). We showed that Che-1 can be covalently modified by PARP1 in a in vitro poly(ADP-ribosyl)ation reaction. Further on, immunoprecipitation experiments confirmed the existence of a poly(ADP-ribosyl)ated form of Che-1 in Doxo treated cells (Figure 19).

In conclusion, our experiments give a new insight into the mechanisms by which PARP activity orchestrates the signalling transduction in DDR. We demonstrate that poly(ADPribosyl)ation positively regulates Che-1 accumulation through an ATM-independent mechanism (Figure 20).

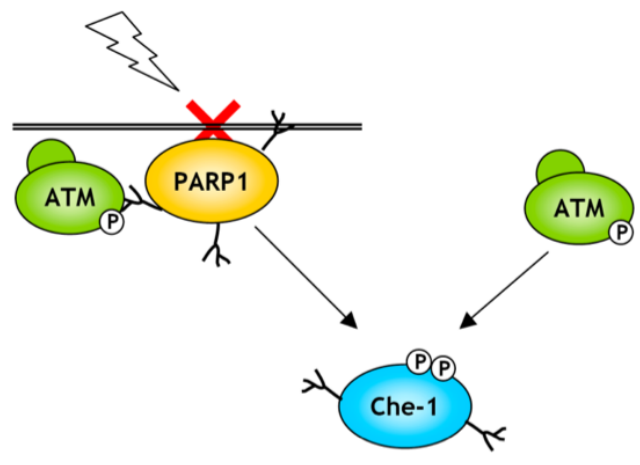

Figure 20. PARP-1 activity promotes stabilization of Che-1 in response to DNA damage.

Upon DNA lesions, poly(ADP-ribosyl)ation by PARP-1 and phosphorylation by ATM act in parallel pathways to promote stabilization of Che-1. These post-translational modifications enable the precise control over the level of Che-1 protein in response to DNA damage.

Further experiments will have to address how Che-1 modification by PARP-1 promotes its accumulation, and here we discuss some possible mechanisms. One possible explanation is that covalent poly(ADP-ribosyl)ation of Che-1 contributes to protect it from proteosomal degradation, as has been demonstrated for p53 (Won et al., 2006) and histone proteins 
(Catalgol et al., 2009). Che-1 seems to be preferentially modified by a low number of ADPribose molecules in vivo, as shown by the absence of a band shift in immunoprecipitations (Figure 17B and Figure 19B, C). We can speculate that oligo(ADP-ribosyl)ation of Che-1 is important to avoid protein degradation, since it has been reported that interaction with the proteasome is restricted to long poly(ADP-ribose) molecules (Mayer-Kuckuk et al., 1999). Another possible explanation is that addition of PAR to Che-1 alters its binding properties, for example facilitating its interaction with a DDR kinase. Since we demonstrated that poly(ADPribosyl)ation does not modulate Che-1 accumulation through ATM, it could act through Chk2, the other kinase strongly involved in Che-1 stabilization. An interaction between PAR and Chk2 has never been described, but notably Chk2 from Dictyostelium discoideum contains a newly identified PAR-binding motif (Ahel et al., 2008). This region is not conserved in human Chk2, but it could still retain the ability to bind PAR by an alternative motif. In this case poly(ADP-ribosyl)ation of Che-1 would represent a fine mechanism to modulate Che-1 phosphorylation and accumulation.

Understanding the mechanism through which PARP inhibition acts on Che-1 level in DDR can help in the development of new antitumoral agents. Silencing of Che-1 abolishes the maintaining of $\mathrm{G} 2 / \mathrm{M}$ checkpoint and sensitizes tumor but not normal cells to anticancer drugs (Bruno et al., 2006). The potent antitumoral effect of some PARP inhibitors could be due in part to their ability to suppress activation of checkpoints after DNA damage induced by chemotherapic drugs (Bryant et al., 2005; Fong et al., 2009; Helleday et al., 2008; Rouleau et al., 2010; Munoz-Gamez et al., 2010). Our findings suggest that the reduction of Che-1 stabilization upon PARP inhibition could represent one of the mechanisms by which PARP inhibitors exert their antitumoral effects. 


\section{REFERENCES}

Abraham, R.T. 2001. Cell cycle checkpoint signaling through the ATM and ATR kinases. Genes \& Development. 15:2177-2196.

Aguilar-Quesada, R., J.A. Munoz-Gamez, D. Martin-Oliva, A. Peralta, M.T. Valenzuela, R. Matinez-Romero, R. Quiles-Perez, J. Menissier-de Murcia, G. de Murcia, M. Ruiz de Almodovar, and F.J. Oliver. 2007. Interaction between ATM and PARP-1 in response to DNA damage and sensitization of ATM deficient cells through PARP inhibition. BMC Mol Biol. 8:29.

Ahel, D., Z. Horejsi, N. Wiechens, S.E. Polo, E. Garcia-Wilson, I. Ahel, H. Flynn, M. Skehel, S.C. West, S.P. Jackson, T. Owen-Hughes, and S.J. Boulton. 2009. Poly(ADP-ribose)dependent regulation of DNA repair by the chromatin remodeling enzyme ALC1. Science. 325:1240-3.

Ahel, I., D. Ahel, T. Matsusaka, A.J. Clark, J. Pines, S.J. Boulton, and S.C. West. 2008. Poly(ADP-ribose)-binding zinc finger motifs in DNA repair/checkpoint proteins. Nature. 451:81-5.

Altmeyer, M., S. Messner, P.O. Hassa, M. Fey, and M.O. Hottiger. 2009. Molecular mechanism of poly(ADP-ribosyl)ation by PARP1 and identification of lysine residues as ADP-ribose acceptor sites. Nucleic Acids Res. 37:3723-38.

Andersen, J.S., Y.W. Lam, A.K. Leung, S.E. Ong, C.E. Lyon, A.I. Lamond, and M. Mann. 2005. Nucleolar proteome dynamics. Nature. 433:77-83.

Bakkenist, C.J., and M.B. Kastan. 2003. DNA damage activates ATM through intermolecular autophosphorylation and dimer dissociation. Nature. 421:499-506.

Barbato, C., N. Corbi, N. Canu, M. Fanciulli, A. Serafino, M. Ciotti, V. Libri, T. Bruno, G. Amadoro, R. De Angelis, P. Calissano, and C. Passananti. 2003. Rb binding protein Che-1 interacts with Tau in cerebellar granule neurons. Modulation during neuronal apoptosis. Mol Cell Neurosci. 24:1038-50.

Bartkova, J., Z. Horejsí, K. Koed, A. Krämer, F. Tort, K. Zieger, P. Guldberg, M. Sehested, J.M. Nesland, C. Lukas, T. Ørntoft, J. Lukas, and J. Bartek. 2005. DNA damage response as a candidate anti-cancer barrier in early human tumorigenesis. Nature. 434:864-870.

Bauer, P.I., H.J. Chen, E. Kenesi, I. Kenessey, K.G. Buki, E. Kirsten, A. Hakam, J.I. Hwang, and E. Kun. 2001. Molecular interactions between poly(ADP-ribose) polymerase 
(PARP I) and topoisomerase I (Topo I): identification of topology of binding. FEBS Lett. 506:239-42.

Bruno, T., R. De Angelis, F. De Nicola, C. Barbato, M. Di Padova, N. Corbi, V. Libri, B. Benassi, E. Mattei, A. Chersi, S. Soddu, A. Floridi, C. Passananti, and M. Fanciulli. 2002. Che-1 affects cell growth by interfering with the recruitment of HDAC1 by Rb. Cancer Cell. 2:387-99.

Bruno, T., F. De Nicola, S. Iezzi, D. Lecis, C. D'Angelo, M. Di Padova, N. Corbi, L. Dimiziani, L. Zannini, C. Jekimovs, M. Scarsella, A. Porrello, A. Chersi, M. Crescenzi, C. Leonetti, K.K. Khanna, S. Soddu, A. Floridi, C. Passananti, D. Delia, and M. Fanciulli. 2006. Che-1 phosphorylation by ATM/ATR and Chk2 kinases activates p53 transcription and the G2/M checkpoint. Cancer Cell. 10:473-86.

Bruno, T., A. Desantis, G. Bossi, S. Di Agostino, C. Sorino, F. De Nicola, S. Iezzi, A. Franchitto, B. Benassi, S. Galanti, F. La Rosa, A. Floridi, A. Bellacosa, C. Passananti, G. Blandino, and M. Fanciulli. 2010. Che-1 promotes tumor cell survival by sustaining mutant p53 transcription and inhibiting DNA damage response activation. Cancer Cell. 18:122-134.

Bryant, H.E., and T. Helleday. 2006. Inhibition of poly (ADP-ribose) polymerase activates ATM which is required for subsequent homologous recombination repair. Nucleic Acids Res. 34:1685-91.

Bryant, H.E., N. Schultz, H.D. Thomas, K.M. Parker, D. Flower, E. Lopez, S. Kyle, M. Meuth, N.J. Curtin, and T. Helleday. 2005. Specific killing of BRCA2-deficient tumours with inhibitors of poly(ADP-ribose) polymerase. Nature. 434:913-7.

Burgdorf, S., P. Leister, and K.H. Scheidtmann. 2004. TSG101 interacts with apoptosisantagonizing transcription factor and enhances androgen receptor-mediated transcription by promoting its monoubiquitination. The Journal of Biological Chemistry. 279:17524-17534.

Carrozza, M.J., D.F. Stefanick, J.K. Horton, P.S. Kedar, and S.H. Wilson. 2009. PARP inhibition during alkylation-induced genotoxic stress signals a cell cycle checkpoint response mediated by ATM. DNA Repair (Amst). 8:1264-72.

Catalgol, B., B. Wendt, S. Grimm, N. Breusing, N.K. Ozer, and T. Grune. 2009. Chromatin repair after oxidative stress: Role of PARP-mediated proteasome activation. Free Radic Biol Med.

Cimprich, K.A., and D. Cortez. 2008. ATR: an essential regulator of genome integrity. Nature Reviews. Molecular Cell Biology. 9:616-627. 
Cohausz, O., C. Blenn, M. Malanga, and F.R. Althaus. 2008. The roles of poly(ADP-ribose)metabolizing enzymes in alkylation-induced cell death. Cell Mol Life Sci. 65:644-55.

Cregan, S.P., A. Fortin, J.G. MacLaurin, S.M. Callaghan, F. Cecconi, S.W. Yu, T.M. Dawson, V.L. Dawson, D.S. Park, G. Kroemer, and R.S. Slack. 2002. Apoptosisinducing factor is involved in the regulation of caspase-independent neuronal cell death. J Cell Biol. 158:507-17.

D'Amours, D., S. Desnoyers, I. D'Silva, and G.G. Poirier. 1999. Poly(ADP-ribosyl)ation reactions in the regulation of nuclear functions. Biochem J. 342 ( Pt 2):249-68.

De Nicola, F., T. Bruno, S. Iezzi, M. Di Padova, A. Floridi, C. Passananti, G. Del Sal, and M. Fanciulli. 2007. The prolyl isomerase Pin1 affects Che-1 stability in response to apoptotic DNA damage. J Biol Chem. 282:19685-91.

Delacroix, S., J.M. Wagner, M. Kobayashi, K.-i. Yamamoto, and L.M. Karnitz. 2007. The Rad9-Hus1-Rad1 (9-1-1) clamp activates checkpoint signaling via TopBP1. Genes \& Development. 21:1472-1477.

Dellaire, G., and D.P. Bazett-Jones. 2007. Beyond repair foci: subnuclear domains and the cellular response to DNA damage. Cell Cycle. 6:1864-72.

Di Certo, M.G., N. Corbi, T. Bruno, S. Iezzi, F. De Nicola, A. Desantis, M.T. Ciotti, E. Mattei, A. Floridi, M. Fanciulli, and C. Passananti. 2007. NRAGE associates with the anti-apoptotic factor Che-1 and regulates its degradation to induce cell death. Journal of Cell Science. 120:1852-1858.

Di Padova, M., T. Bruno, F. De Nicola, S. Iezzi, C. D'Angelo, R. Gallo, D. Nicosia, N. Corbi, A. Biroccio, A. Floridi, C. Passananti, and M. Fanciulli. 2003. Che-1 arrests human colon carcinoma cell proliferation by displacing HDAC1 from the p21WAF1/CIP1 promoter. The Journal of Biological Chemistry. 278:36496-36504.

El-Khamisy, S.F., M. Masutani, H. Suzuki, and K.W. Caldecott. 2003. A requirement for PARP-1 for the assembly or stability of XRCC1 nuclear foci at sites of oxidative DNA damage. Nucleic Acids Res. 31:5526-33.

Fanciulli, M., T. Bruno, M. Di Padova, R. De Angelis, S. Iezzi, C. Iacobini, A. Floridi, and C. Passananti. 2000. Identification of a novel partner of RNA polymerase II subunit 11, Che-1, which interacts with and affects the growth suppression function of Rb. Faseb J. 14:904-12.

Fong, P.C., D.S. Boss, T.A. Yap, A. Tutt, P. Wu, M. Mergui-Roelvink, P. Mortimer, H. Swaisland, A. Lau, M.J. O'Connor, A. Ashworth, J. Carmichael, S.B. Kaye, J.H. 
Schellens, and J.S. de Bono. 2009. Inhibition of poly(ADP-ribose) polymerase in tumors from BRCA mutation carriers. N Engl J Med. 361:123-34.

Freire, R., M.A.T.M. van Vugt, I. Mamely, and R.H. Medema. 2006. Claspin: timing the cell cycle arrest when the genome is damaged. Cell Cycle (Georgetown, Tex.). 5:28312834.

Gagne, J.P., M. Isabelle, K.S. Lo, S. Bourassa, M.J. Hendzel, V.L. Dawson, T.M. Dawson, and G.G. Poirier. 2008. Proteome-wide identification of poly(ADP-ribose) binding proteins and poly(ADP-ribose)-associated protein complexes. Nucleic Acids Res. 36:6959-76.

Goodarzi, A.A., and S.P. Lees-Miller. 2004. Biochemical characterization of the ataxiatelangiectasia mutated (ATM) protein from human cells. DNA Repair (Amst). 3:75367.

Gorgoulis, V.G., L.-V.F. Vassiliou, P. Karakaidos, P. Zacharatos, A. Kotsinas, T. Liloglou, M. Venere, R.A. Ditullio, N.G. Kastrinakis, B. Levy, D. Kletsas, A. Yoneta, M. Herlyn, C. Kittas, and T.D. Halazonetis. 2005. Activation of the DNA damage checkpoint and genomic instability in human precancerous lesions. Nature. 434:907913.

Gottschalk, A.J., G. Timinszky, S.E. Kong, J. Jin, Y. Cai, S.K. Swanson, M.P. Washburn, L. Florens, A.G. Ladurner, J.W. Conaway, and R.C. Conaway. 2009. Poly(ADPribosyl)ation directs recruitment and activation of an ATP-dependent chromatin remodeler. Proc Natl Acad Sci U S A. 106:13770-4.

Guo, Q., and J. Xie. 2004. AATF inhibits aberrant production of amyloid beta peptide 1-42 by interacting directly with Par-4. The Journal of Biological Chemistry. 279:4596-4603.

Haince, J.F., S. Kozlov, V.L. Dawson, T.M. Dawson, M.J. Hendzel, M.F. Lavin, and G.G. Poirier. 2007. Ataxia telangiectasia mutated (ATM) signaling network is modulated by a novel poly(ADP-ribose)-dependent pathway in the early response to DNA-damaging agents. J Biol Chem. 282:16441-53.

Hakem, R. 2008. DNA-damage repair; the good, the bad, and the ugly. The EMBO Journal. 27:589-605.

Harper, J.W., and S.J. Elledge. 2007. The DNA damage response: ten years after. Mol Cell. 28:739-45.

Hassa, P.O., M. Covic, S. Hasan, R. Imhof, and M.O. Hottiger. 2001. The enzymatic and DNA binding activity of PARP-1 are not required for NF-kappa B coactivator function. J Biol Chem. 276:45588-97. 
Hegan, D.C., Y. Lu, G.C. Stachelek, M.E. Crosby, R.S. Bindra, and P.M. Glazer. 2010. Inhibition of poly(ADP-ribose) polymerase down-regulates BRCA1 and RAD51 in a pathway mediated by E2F4 and p130. Proc Natl Acad Sci U S A. 107:2201-6.

Helleday, T., E. Petermann, C. Lundin, B. Hodgson, and R.A. Sharma. 2008. DNA repair pathways as targets for cancer therapy. Nat Rev Cancer. 8:193-204.

Hirao, A., A. Cheung, G. Duncan, P.M. Girard, A.J. Elia, A. Wakeham, H. Okada, T. Sarkissian, J.A. Wong, T. Sakai, E. De Stanchina, R.G. Bristow, T. Suda, S.W. Lowe, P.A. Jeggo, S.J. Elledge and T.W. Mak. 2002. Chk2 is a tumor suppressor that regulates apoptosis in both an ataxia telangiectasia mutated (ATM)-dependent and an ATM-independent manner. Mol Cell Biol. 22:6521-6532.

Horton, J.K., D.F. Stefanick, J.M. Naron, P.S. Kedar, and S.H. Wilson. 2005. Poly(ADPribose) polymerase activity prevents signaling pathways for cell cycle arrest after DNA methylating agent exposure. The Journal of Biological Chemistry. 280:1577315785.

Hottiger, M.O., P.O. Hassa, B. Luscher, H. Schuler, and F. Koch-Nolte. 2010. Toward a unified nomenclature for mammalian ADP-ribosyltransferases. Trends Biochem Sci. 35:208-19.

Huen, M.S., and J. Chen. 2008. The DNA damage response pathways: at the crossroad of protein modifications. Cell Res. 18:8-16.

Jackson, S.P., and J. Bartek. 2009. The DNA-damage response in human biology and disease. Nature. 461:1071-8.

Jazayeri, A., J. Falck, C. Lukas, J. Bartek, G.C.M. Smith, J. Lukas, and S.P. Jackson. 2006. ATM- and cell cycle-dependent regulation of ATR in response to DNA double-strand breaks. Nature Cell Biology. 8:37-45.

Kaneko, Y.S., N. Watanabe, H. Morisaki, H. Akita, A. Fujimoto, K. Tominaga, M. Terasawa, A. Tachibana, K. Ikeda, M. Nakanishi, and Y. Kaneko. 1999. Cell-cycle-dependent and ATM-independent expression of human Chk1 kinase. Oncogene. 18:3673-3681.

Kawanishi, S., Y. Hiraku, S. Pinlaor, and N. Ma. 2006. Oxidative and nitrative DNA damage in animals and patients with inflammatory diseases in relation to inflammation-related carcinogenesis. Biological Chemistry. 387:365-372.

Kozlov, S.V., M.E. Graham, C. Peng, P. Chen, P.J. Robinson, and M.F. Lavin. 2006. Involvement of novel autophosphorylation sites in ATM activation. The EMBO Journal. 25:3504-3514.

Kraus, W.L., and J.T. Lis. 2003. PARP goes transcription. Cell. 113:677-83. 
Krishnakumar, R., and W.L. Kraus. 2010. The PARP side of the nucleus: molecular actions, physiological outcomes, and clinical targets. Mol Cell. 39:8-24.

Langelier, M.F., K.M. Servent, E.E. Rogers, and J.M. Pascal. 2008. A third zinc-binding domain of human poly(ADP-ribose) polymerase-1 coordinates DNA-dependent enzyme activation. J Biol Chem. 283:4105-14.

Lee, J.-H., and T.T. Paull. 2005. ATM activation by DNA double-strand breaks through the Mre11-Rad50-Nbs1 complex. Science (New York, N.Y.). 308:551-554.

Leppard, J.B., Z. Dong, Z.B. Mackey, and A.E. Tomkinson. 2003. Physical and functional interaction between DNA ligase IIIalpha and poly(ADP-Ribose) polymerase 1 in DNA single-strand break repair. Mol Cell Biol. 23:5919-27.

Li, J. and D.F. Stern. 2005 Regulation of CHK2 by DNA-dependent protein kinase. J Biol Chem. 280:12041-12050

Lindahl, T., and D.E. Barnes. 2000. Repair of endogenous DNA damage. Cold Spring Harbor Symposia on Quantitative Biology. 65:127-133.

Madison, D.L., and J.R. Lundblad. 2010. C-terminal binding protein and poly(ADP)ribose polymerase 1 contribute to repression of the p21(waf1/cip1) promoter. Oncogene. 29:6027-39.

Malanga, M., J.M. Pleschke, H.E. Kleczkowska, and F.R. Althaus. 1998. Poly(ADP-ribose) binds to specific domains of p53 and alters its DNA binding functions. $J$ Biol Chem. 273:11839-43.

Matsuoka, S., G. Rotman, A. Ogawa, Y. Shiloh, K. Tamai, S.J. Elledge. Ataxia telangiectasiamutated phosphorylates Chk2 in vivo and in vitro. 2000. Proc Natl Acad Sci U S A. 97:10389-10394.

Matsuoka, S., B.A. Ballif, A. Smogorzewska, E.R. McDonald, K.E. Hurov, J. Luo, C.E. Bakalarski, Z. Zhao, N. Solimini, Y. Lerenthal, Y. Shiloh, S.P. Gygi, and S.J. Elledge. 2007. ATM and ATR substrate analysis reveals extensive protein networks responsive to DNA damage. Science (New York, N.Y.). 316:1160-1166.

Mayer-Kuckuk, P., O. Ullrich, M. Ziegler, T. Grune, and M. Schweiger. 1999. Functional interaction of poly(ADP-ribose) with the $20 \mathrm{~S}$ proteasome in vitro. Biochem Biophys Res Commun. 259:576-81.

McCabe, N., N.C. Turner, C.J. Lord, K. Kluzek, A. Bialkowska, S. Swift, S. Giavara, M.J. O'Connor, A.N. Tutt, M.Z. Zdzienicka, G.C. Smith, and A. Ashworth. 2006. Deficiency in the repair of DNA damage by homologous recombination and sensitivity to poly(ADP-ribose) polymerase inhibition. Cancer Res. 66:8109-15. 
Meder, V.S., M. Boeglin, G. de Murcia, and V. Schreiber. 2005. PARP-1 and PARP-2 interact with nucleophosmin/B23 and accumulate in transcriptionally active nucleoli. $J$ Cell Sci. 118:211-22.

Mendoza-Alvarez, H., and R. Alvarez-Gonzalez. 1993. Poly(ADP-ribose) polymerase is a catalytic dimer and the automodification reaction is intermolecular. J Biol Chem. 268:22575-80.

Munoz-Gamez, J.A., R. Quiles-Perez, A. Ruiz-Extremera, A.B. Martin-Alvarez, L. SanjuanNunez, A. Carazo, J. Leon, F.J. Oliver, and J. Salmeron. 2010. Inhibition of poly (ADP-ribose) polymerase-1 enhances doxorubicin activity against liver cancer cells. Cancer Lett.

Oei, S.L., J. Griesenbeck, M. Schweiger, V. Babich, A. Kropotov, and N. Tomilin. 1997. Interaction of the transcription factor YY1 with human poly(ADP-ribosyl) transferase. Biochem Biophys Res Commun. 240:108-11.

Okano, S., L. Lan, K.W. Caldecott, T. Mori, and A. Yasui. 2003. Spatial and temporal cellular responses to single-strand breaks in human cells. Molecular and Cellular Biology. 23:3974-3981.

Page, G., I. Lödige, D. Kögel, and K.H. Scheidtmann. 1999. AATF, a novel transcription factor that interacts with Dlk/ZIP kinase and interferes with apoptosis. FEBS Letters. 462:187-191.

Panzeter, P.L., C.A. Realini, and F.R. Althaus. 1992. Noncovalent interactions of poly(adenosine diphosphate ribose) with histones. Biochemistry. 31:1379-85.

Passananti, C., A. Floridi, and M. Fanciulli. 2007. Che-1/AATF, a multivalent adaptor connecting transcriptional regulation, checkpoint control, and apoptosis. Biochemistry and Cell Biology = Biochimie Et Biologie Cellulaire. 85:477-483.

Pleschke, J.M., H.E. Kleczkowska, M. Strohm, and F.R. Althaus. 2000. Poly(ADP-ribose) binds to specific domains in DNA damage checkpoint proteins. J Biol Chem. 275:40974-80.

Rancourt, A., and M.S. Satoh. 2009. Delocalization of nucleolar poly(ADP-ribose) polymerase-1 to the nucleoplasm and its novel link to cellular sensitivity to DNA damage. DNA Repair (Amst). 8:286-97.

Reale, A., G.D. Matteis, G. Galleazzi, M. Zampieri, and P. Caiafa. 2005. Modulation of DNMT1 activity by ADP-ribose polymers. Oncogene. 24:13-9.

Reinhardt, H.C., H. Jiang, M.T. Hemann, and M.B. Yaffe. 2009. Exploiting synthetic lethal interactions for targeted cancer therapy. Cell Cycle (Georgetown, Tex.). 8:3112-3119. 
Rouleau, M., A. Patel, M.J. Hendzel, S.H. Kaufmann, and G.G. Poirier. 2010. PARP inhibition: PARP1 and beyond. Nat Rev Cancer. 10:293-301.

Shiloh, Y. 2003. ATM and related protein kinases: safeguarding genome integrity. Nat Rev Cancer. 3:155-68.

Simonin, F., O. Poch, M. Delarue, and G. de Murcia. 1993. Identification of potential activesite residues in the human poly(ADP-ribose) polymerase. J Biol Chem. 268:8529-35.

Smith, J., L.M. Tho, N. Xu, and D.A. Gillespie. 2010. The ATM-Chk2 and ATR-Chk1 pathways in DNA damage signaling and cancer. Advances in Cancer Research. 108:73-112.

Stilmann, M., M. Hinz, S.C. Arslan, A. Zimmer, V. Schreiber, and C. Scheidereit. 2009. A nuclear poly(ADP-ribose)-dependent signalosome confers DNA damage-induced IkappaB kinase activation. Mol Cell. 36:365-78.

Stracker, T.H., U. Takehiki and J.H.J. Petrini. 2009. Taking the time to make important decisions: the checkpoint effector kinases Chk1 and Chk2 and the DNA damage response. DNA Repair (Amst). 8: 1047-1054.

Subba Rao, K. 2007. Mechanisms of disease: DNA repair defects and neurological disease. Nature Clinical Practice. Neurology. 3:162-172.

Tao, Z., P. Gao, and H.W. Liu. 2009. Identification of the ADP-ribosylation sites in the PARP-1 automodification domain: analysis and implications. $J$ Am Chem Soc. 131:14258-60.

Tavassoli, M., M.H. Tavassoli, and S. Shall. 1985. Effect of DNA intercalators on poly(ADPribose) glycohydrolase activity. Biochim Biophys Acta. 827:228-34.

Thomas, T., A.K. Voss, P. Petrou, and P. Gruss. 2000. The murine gene, Traube, is essential for the growth of preimplantation embryos. Developmental Biology. 227:324-342.

Thoms, K.-M., C. Kuschal, and S. Emmert. 2007. Lessons learned from DNA repair defective syndromes. Experimental Dermatology. 16:532-544.

Timinszky, G., S. Till, P.O. Hassa, M. Hothorn, G. Kustatscher, B. Nijmeijer, J. Colombelli, M. Altmeyer, E.H. Stelzer, K. Scheffzek, M.O. Hottiger, and A.G. Ladurner. 2009. A macrodomain-containing histone rearranges chromatin upon sensing PARP1 activation. Nat Struct Mol Biol. 16:923-9.

Tong, W.M., U. Cortes, and Z.Q. Wang. 2001. Poly(ADP-ribose) polymerase: a guardian angel protecting the genome and suppressing tumorigenesis. Biochim Biophys Acta. 1552:27-37. 
Wang, Z.Q., B. Auer, L. Stingl, H. Berghammer, D. Haidacher, M. Schweiger, and E.F. Wagner. 1995. Mice lacking ADPRT and poly(ADP-ribosyl)ation develop normally but are susceptible to skin disease. Genes Dev. 9:509-20.

Watanabe, F., H. Fukazawa, M. Masutani, H. Suzuki, H. Teraoka, S. Mizutani, and Y. Uehara. 2004. Poly(ADP-ribose) polymerase-1 inhibits ATM kinase activity in DNA damage response. Biochem Biophys Res Commun. 319:596-602.

Wieler, S., J.P. Gagne, H. Vaziri, G.G. Poirier, and S. Benchimol. 2003. Poly(ADP-ribose) polymerase-1 is a positive regulator of the p53-mediated G1 arrest response following ionizing radiation. J Biol Chem. 278:18914-21.

Won, J., S.Y. Chung, S.B. Kim, B.H. Byun, Y.S. Yoon, and C.O. Joe. 2006. Dose-dependent UV stabilization of p53 in cultured human cells undergoing apoptosis is mediated by poly(ADP-ribosyl)ation. Mol Cells. 21:218-23.

Xie, J., and Q. Guo. 2004. AATF protects neural cells against oxidative damage induced by amyloid beta-peptide. Neurobiology of Disease. 16:150-157.

Yung, T.M., S. Sato, and M.S. Satoh. 2004. Poly(ADP-ribosyl)ation as a DNA damageinduced post-translational modification regulating poly(ADP-ribose) polymerase-1topoisomerase I interaction. J Biol Chem. 279:39686-96.

Zampieri, M., C. Passananti, R. Calabrese, M. Perilli, N. Corbi, F. De Cave, T. Guastafierro, M.G. Bacalini, A. Reale, G. Amicosante, L. Calabrese, J. Zlatanova and P. Caiafa. 2009. Parp1 localizes within the Dnmt1 promoter and protects its unmethylated state by its enzymatic activity, PloS one, 4, e4717.

Zhou, B.-B.S., and J. Bartek. 2004. Targeting the checkpoint kinases: chemosensitization versus chemoprotection. Nature Reviews. Cancer. 4:216-225.

Zou, L., and S.J. Elledge. 2003. Sensing DNA damage through ATRIP recognition of RPAssDNA complexes. Science (New York, N.Y.). 300:1542-1548. 


\section{GgRGAIE}

GR.AZIE alla Prof.ssa Anba Reale, perchè è stata un'ínsegrnante ed un'amica...oh mio DiO!

GrRAZIE alla Prof.ssa Paola Caiafa, perchè mi ha sempre sosteruto ed incoragsiato con un sorriso

GRALIE ai miei compagni di laboratorio, perchè hapbo sopportato il mio disordine e hapro condiviso con me i momenti belli e quelli di difficoltà. in particolare:

GRARIE a Tizi per le nostre inconfessabili confidenze

GrRAZIE a Robby perchè non siamo apcora troppo vecchic per andare ad un concerto di Shantel

GrR.AZIE a Eabio perchè ha sempre sopportato le mie elucubrazioni mebtali (è abbastanza arcana la parola elucubrazioni?)

GraAZIE a Micky perchè...pensavo...hai il protocollo per fare la fissione pucleare?

GrRAZIE a Fabrizio, Antonietta, Patrizia e allae guardic Erapcesco e Fabrizio, per avermi regalato un sorriso alb'arrivo e ubo all'uscita

ĢRAZIF ad Alessandro, Linda e Giulietta. Vabbè, to confesso... mi gasa troppo che ti chiami come me!

GR.AZIE alla lunga lista dei miei coinquilini romani, ed in particolare a Gina, Neal, Monica, Claudia e Cristian, perchè una parola scambiata con śli amici 
dopo una giornata di lavoro pon ha prezzo. Un grzie particolare a Gina, per la pazienza ed i consigli, e perchè è una persona speciale.

GrRAZIE alle mie amiche di sempre: Simona, Gioia, Elena, Beredetta, Alessandra ed Erika, perchè continuano ad esserci sempre

GRAAZIE a mia mamma e a mio papà, perchè stavolta veramente mi habro sopportato e supportato tanto. Grazie a Maria Claudia a a Nicolò, perchè ci sarà sempre un Fabtaghirò da guardare assieme a Natale

GRRAZIE a Valebtina, Eabrizio, Antonio e Melina (Eabbrizio e Vale, preparatevi alla prossima sfida con la Wiil E va bebe, Antonio, puoi giocare abche tu!)

GRAAZIE agli amici di Bologha, สuebli vecchi e बuelli puovi

GRAZIE a Pierangelo, perchè ora sono veramente felice.

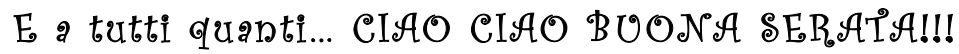

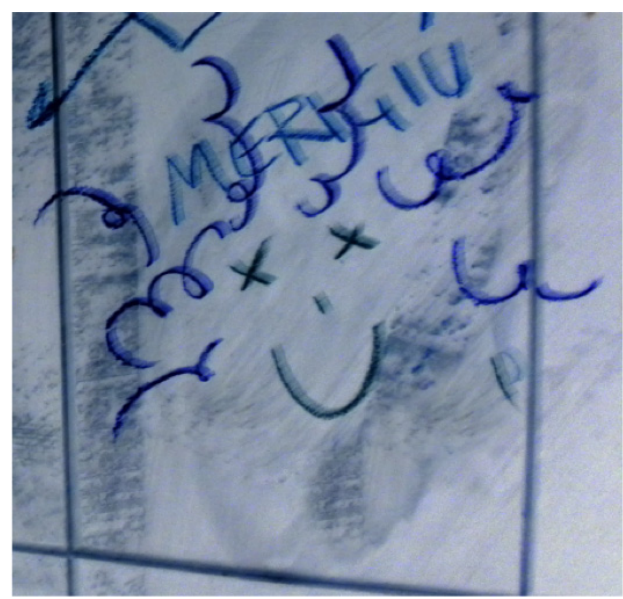

